\title{
HIFiRE Direct-Connect Rig (HDCR) Phase I Scramjet Test Results from the NASA Langley Arc-Heated Scramjet Test Facility
}

\author{
Karen Cabell ${ }^{*}$ and Neal Hass ${ }^{\dagger}$ \\ NASA Langley Research Center, Hampton, Virginia 23861 \\ Andrea Storch \\ ATK Space Systems, NASA Langley Research Center, Hampton, Virginia 23861 \\ Mark Gruber ${ }^{\S}$ \\ Air Force Research Laboratory, Wright-Patterson AFB, Ohio 45433
}

\begin{abstract}
A series of hydrocarbon-fueled direct-connect scramjet ground tests has been completed in the NASA Langley Arc-Heated Scramjet Test Facility (AHSTF) at simulated Mach 8 flight conditions. These experiments were part of an initial test phase to support Flight 2 of the Hypersonic International Flight Research Experimentation (HIFiRE) Program. In this flight experiment, a hydrocarbon-fueled scramjet is intended to demonstrate transition from dual-mode to scramjet-mode operation and verify the scramjet performance prediction and design tools A performance goal is the achievement of a combusted fuel equivalence ratio greater than 0.7 while in scramjet mode. The ground test rig, designated the HIFiRE Direct Connect Rig (HDCR), is a full-scale, heat sink test article that duplicates both the flowpath lines and a majority of the instrumentation layout of the isolator and combustor portion of the flight test hardware. The primary objectives of the HDCR Phase I tests were to verify the operability of the HIFiRE isolator/combustor across the simulated Mach $6-8$ flight regime and to establish a fuel distribution schedule to ensure a successful mode transition. Both of these objectives were achieved prior to the HiFIRE Flight 2 payload Critical Design Review. Mach 8 ground test results are presented in this report, including flowpath surface pressure distributions that demonstrate the operation of the flowpath in scramjet-mode over a small range of test conditions around the nominal Mach 8 simulation, as well as over a range of fuel equivalence ratios. Flowpath analysis using ground test data is presented elsewhere; however, limited comparisons with analytical predictions suggest that both scramjet-mode operation and the combustion performance objective are achieved at Mach 8 conditions.
\end{abstract}

\section{Nomenclature}

$M_{I D} \quad=$ one-dimensional Mach number

$M_{\infty}=$ simulated flight Mach number

$q_{\infty} \quad=\quad$ simulated flight dynamic pressure (psf)

$P_{t} \quad=$ facility plenum stagnation pressure (psia)

$H_{t} \quad=$ facility plenum stagnation enthalpy $\left(\mathrm{Btu} / \mathrm{lb}_{\mathrm{m}}\right)$

$\phi \quad=$ fuel equivalence ratio

$\phi_{P I}=$ fuel equivalence ratio injected at primary injection station

$\phi_{C I}=$ fuel equivalence ratio injected at cavity injection station

\footnotetext{
* Aerospace Engineer, Hypersonic Airbreathing Propulsion Branch.

${ }^{+}$Aerospace Engineer, Hypersonic Airbreathing Propulsion Branch. Senior Member.

${ }^{\ddagger}$ Aerospace Engineer, ATK/Hypersonic Airbreathing Propulsion Branch. Senior Member.

$\S$ Principal Aerospace Engineer, AFRL/RZAS. Associate Fellow.
} 


$$
\begin{array}{ll}
\phi_{S I} & =\text { fuel equivalence ratio injected at secondary injection station } \\
\phi_{T O T} & =\text { total equivalence ratio }=\phi_{P I}+\phi_{C I}+\phi_{S 1} \\
\phi_{B} & =\text { total fuel equivalence ratio burned } \\
x & =\text { axial distance from isolator entrance (in) } \\
t & =\text { time (seconds) }
\end{array}
$$

Acronyms

AFRL $=$ Air Force Research Laboratory
AHSTF $=$ Arc-Heated Scramjet Test Facility
DSTO $=$ Defence Science and Technology Organisation
HDCR $=$ HIFiRE Direct Connect Rig
HF2 $=$ HIFiRE Flight 2
HIFiRE $=$ Hypersonic International Flight Research Experimentation
NIST $=$ National Institute of Standards and Technology
TBC $=$ Thermal Barrier Coating

\section{Introduction}

$\mathrm{T}$ The Hypersonic International Flight Research Experimentation (HIFiRE) Program ${ }^{1}$ is a collaborative international effort that aims to study basic hypersonic phenomena through flight experimentation. The objectives of the HIFiRE Program are to increase understanding of fundamental hypersonic phenomena and to develop technologies deemed critical to the realization of next generation aerospace vehicles by extending the hypersonic database and enhancing the accuracy of complex models and simulations. Phenomena will be examined and characterized at flight conditions that are difficult, if not impossible, to model with current computational methods and/or simulate in ground test facilities. The HIFiRE program follows the HyShot ${ }^{2}$ and $\mathrm{HYCAUSE}^{3}$ programs and aims to leverage much of the low-cost flight test techniques developed during those programs.

A number of test flights are planned under the HIFiRE program, with some designated to study the operation, performance, and stability characteristics of hydrocarbon-fueled scramjet combustors. Within this program, the HIFiRE Flight 2 (HF2) ${ }^{4,5,6}$ project team is led by the US Air Force Research Laboratory (AFRL) with NASA and the Australian Defence Science and Technology Organisation (DSTO) as vested partners. HF2 will develop an alternative test technique for acquiring high-enthalpy scramjet flight test data using sounding rockets. Unlike the relatively simple ballistic trajectories employed by HyShot and HYCAUSE, the current approach uses unguided sounding rockets to carry a payload through a test window along a trajectory having nearly constant dynamic pressure but variable Mach number. Using this approach, HF2 will explore Mach 8, hydrocarbon-fueled scramjet performance and dual-mode to scramjet-mode transition in flight. Dual-mode operation is characterized by largescale flow separation, a supersonic core with significant regions of subsonic combusting flow, and combustioninduced pressure rise upstream of the primary fuel injection site. Scramjet-mode operation is characterized by supersonic combusting flow with no large-scale flow separation and minimal combustion-induced pressure rise upstream of the primary fuel injection site. The test fuel is a mixture of ethylene and methane, which serves as a surrogate for an endothermically cracked JP-7 fuel. ${ }^{7}$ The HF2 science objectives are listed in Table 1.

The HF2 payload is shown in Figure 1. The shroud is deployed prior to the flight experiment to expose the scramjet engine. The scramjet flowpath is made up of two opposing forebody ramps that extend back to the sidewalls of the rectangular inlet. ${ }^{8}$ The internal inlet further compresses the flow up to the isolator entrance. The combustor includes a cavity region to promote flameholding. Aft of the combustor, the flow is split with a bifurcating nozzle that vents the flow outward and overboard.

Figure 2 shows the scramjet experiment portion of the nominal HIFiRE trajectory. A three-stage launch system will be used to carry the payload to the initial Mach 5.5 test condition and through the test window to approximately Mach 8.5. In Figure 2, the 'Threshold Test Window' defines the minimum acceptable range of flight test conditions expected from the launch system, while the 'Objective Test Window' defines the desired range of flight test conditions that allow for additional margins on the experiment. After shroud deployment and a brief tare period, the fueling begins at Mach 6.0. The fuel will be injected according to a fuel schedule with a prescribed distribution, or "fuel split" between two injection sites. This fuel schedule was largely developed using the ground test results described here and in Ref. 9. 
Table 1. HIFiRE Flight 2 science objectives.

\begin{tabular}{|c|c|}
\hline \multicolumn{2}{|l|}{ Primary Objectives } \\
\hline Description & HDCR \\
\hline Evaluate scramjet engine performance and operability through a dual-to-scram mode transition & $\checkmark$ \\
\hline Achieve combustion performance of $\phi_{\mathrm{B}} \geq 0.7$ at Mach 8 flight conditions using a hydrocarbon fuel & $\checkmark$ \\
\hline $\begin{array}{l}\text { Demonstrate a scramjet flight test approach that provides a variable Mach number flight corridor at } \\
\text { nearly constant dynamic pressure }\end{array}$ & NA \\
\hline \multicolumn{2}{|l|}{ Secondary Objectives } \\
\hline Description & HDCR \\
\hline Provide a test bed for diode laser-based instrumentation & Phase 2 \\
\hline $\begin{array}{l}\text { Acquire high-fidelity core-flow measurements of combustion products (water) in a scramjet operating } \\
\text { environment up through Mach } 8 \text { flight conditions }\end{array}$ & Phase 2 \\
\hline Evaluate the lean blow-out characteristics of a hydrocarbon fueled scramjet at or above Mach 8 & $\checkmark$ \\
\hline Evaluate a gaseous fuel mixture as a surrogate for a cracked liquid hydrocarbon fuel & $\checkmark$ \\
\hline Validate existing design tools for scramjet inlet, isolator, combustor, and nozzle components & $\checkmark$ \\
\hline
\end{tabular}

To verify engine performance and operability and provide a ground-based data set for later comparison with flight, a ground test rig was developed in parallel with the flight program. Designated the HIFiRE Direct Connect Rig (HDCR), it is a full-scale, heat sink, direct-connect ground test article that duplicates both the flowpath lines and a majority of the instrumentation layout of the isolator and combustor portion of the flight test hardware. The flight objectives which are supported by the HDCR tests are indicated in Table 1. An initial phase of testing has been completed in the NASA Langley Arc-Heated Scramjet Test Facility (AHSTF) at Mach 6 to 8 flight enthalpies. The objectives of the HDCR Phase I tests were to verify that the isolator/combustor portion of the HIFiRE flowpath design demonstrates satisfactory operability, with margin, spanning the engine transition from dual-mode to scramjet-mode operation. The data were used to identify a viable fuel schedule for flight and to benchmark analytical tools used for flight performance and operability predictions. In the initial Mach 6 series of tests, ${ }^{9,10}$ fuel distributions were identified which had satisfactory isolator margin (the percentage of isolator length undisturbed by combustion) for dual-mode operation from Mach 5.8 to 6.5 enthalpies. The specific objectives for the Mach 8 test series included the determination of a fuel distribution which would yield scramjet-mode operation at $\phi_{B}>0.7$ and would have acceptable margin with respect to flameout. Preparations are currenly underway for a second phase of testing to confirm Phase I results, better define operability margins, and test a diode-laser based instrumentation system to be used in flight.

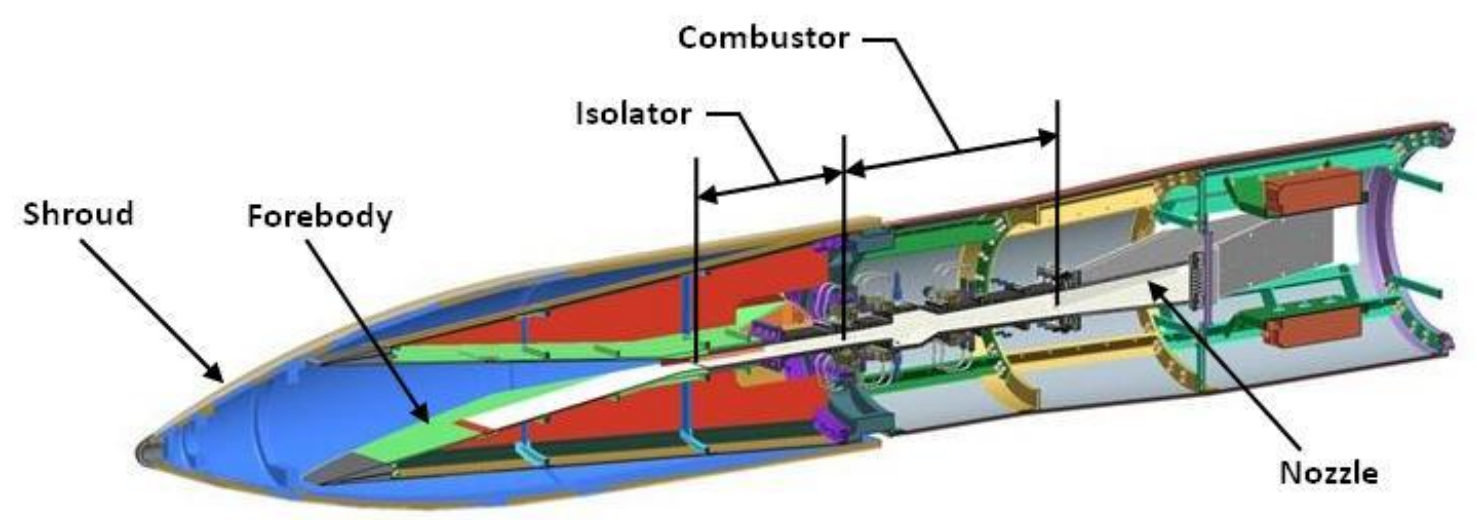

Figure 1. HIFiRE Flight 2 payload cross-section.

American Institute of Aeronautics and Astronautics 


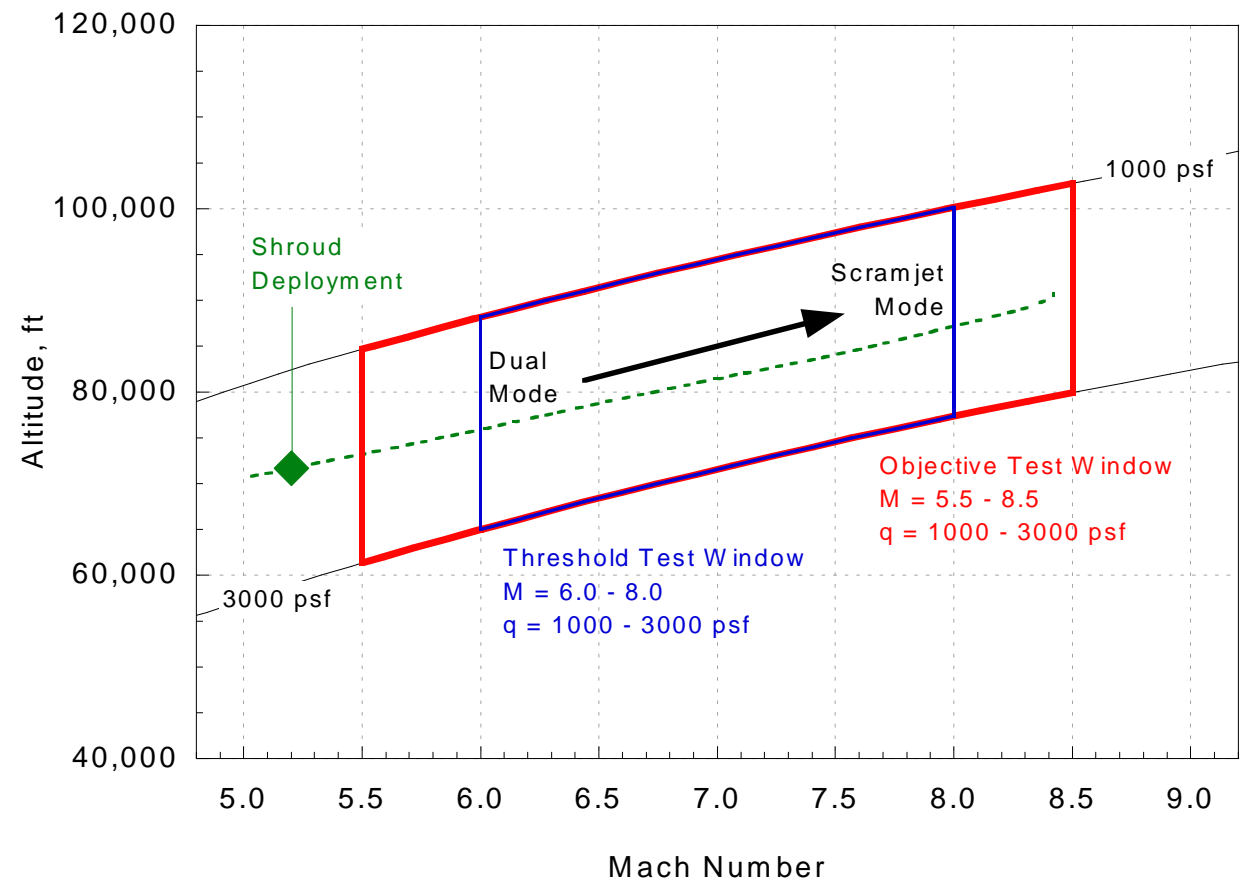

Figure 2. HIFiRE Flight 2 nominal trajectory.

\section{Ground Test Description}

\section{A. Facility Description}

A schematic of the AHSTF is shown in Figure 3. A portion of the air is heated by an electric arc and then mixed with unheated bypass air in a plenum chamber to achieve a desired mixture stagnation enthalpy. The total mixed air stream is expanded through a nozzle and delivered to the test article, which in the case of HDCR, is directly coupled to the nozzle. The mixture stagnation enthalpy is calculated via a sonic throat method using the facility stagnation pressure, total mass flow rate, and nozzle throat area. Note that previous studies ${ }^{11,12}$ have indicated that up to 3 mole percent of nitric oxide is present in the test gas which depletes the $\mathrm{O}_{2}$ content by up to 1.5 percent.

The facility fuel system delivered the flight fuel mixture, which is a molar mixture of $64 \%$ ethylene-36\% methane (a surrogate for endothermically-cracked JP- $7^{7}$ ). A fuel system schematic is shown in Figure 4. As with Mach 6 testing, heating the fuel upstream of expansion processes in the system (i.e., across regulators and flow control valves) was necessary to prevent liquification of the ethylene. From a fuel manifold inside the test cabin,

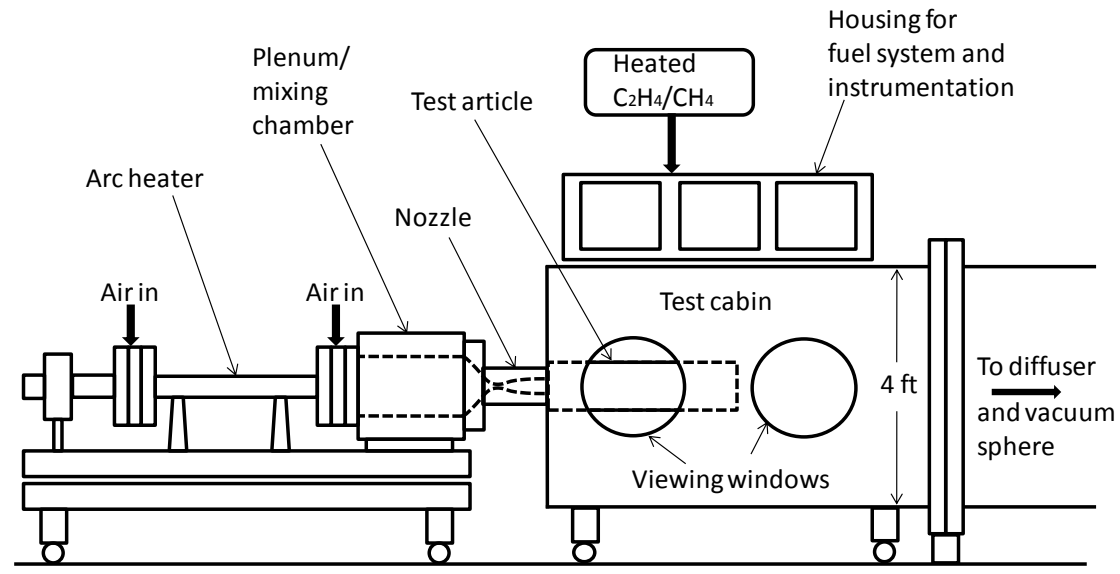

Figure 3. Arc-Heated Scramjet Test Facility schematic. 


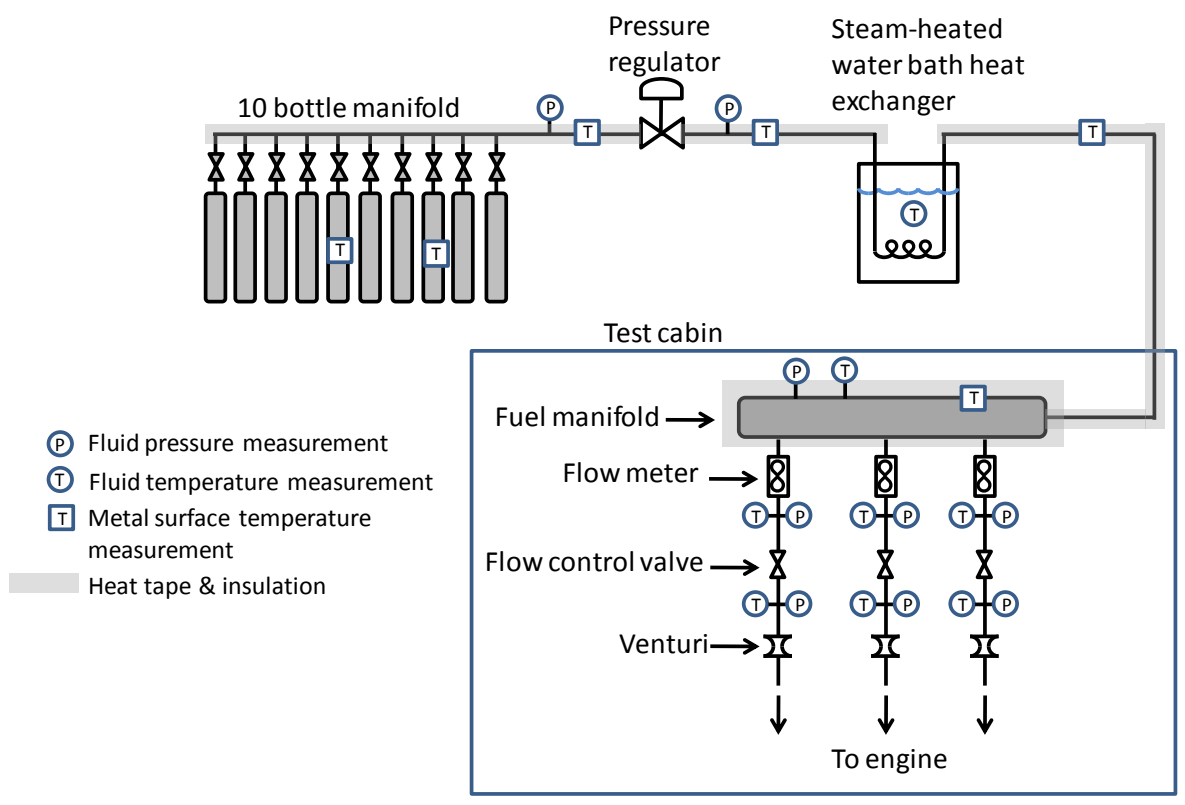

Figure 4. Simplified schematic of HDCR fuel system.

there are three separate legs to independently fuel three injection stations on the engine at a given time. The fuel flow rate was calculated via a sonic flow equation using stagnation pressure and temperature measurements upstream of a calibrated sonic venturi. The NIST software REFPROP ${ }^{13}$ was used to determine the fuel properties required to compute the sonic mass flux for a given stagnation pressure and temperature. Flow meters were also used for an independant check of the fuel flow rate, but the fuel equivalence ratios presented in this report are calculated based on the venturi derived flow rates.

A typical test sequence is shown in Figure 5. Total test time from the beginning of tunnel start-up $(t=0)$ to beginning of shut-down ("Arc-OFF") varies from 20 to 30 seconds, depending on the duration of the engine fueling sequence. Tunnel start-up and the establishment of "steady" conditions in the facility plenum chamber require approximately 12 seconds. This is followed by a 2 second engine tare and the execution of the fuel sequence followed by a 2 second post-fuel tare. Three to four tests were typically conducted per run day. Data were acquired at $10 \mathrm{~Hz}$.

\section{B. Rig Description}

Views of the HDCR are shown in Figure 6. The rig is manufactured from Oxygen-free High Conductivity® (OFHC) copper with wall thicknesses of 2.0 inches. The internal flowpath lines were developed as described in Ref. 14, and are shown in Figure 7. The HDCR duplicates the flowpath of the flight test payload from the entrance of the constant area isolator to the combustor exit (see Figure 1 again). The flowpath width is constant at 4 inches. The overall length of the HDCR is 28.0 inches with an isolator entrance height of $1.0 \mathrm{inch}$, and a combustor exit height

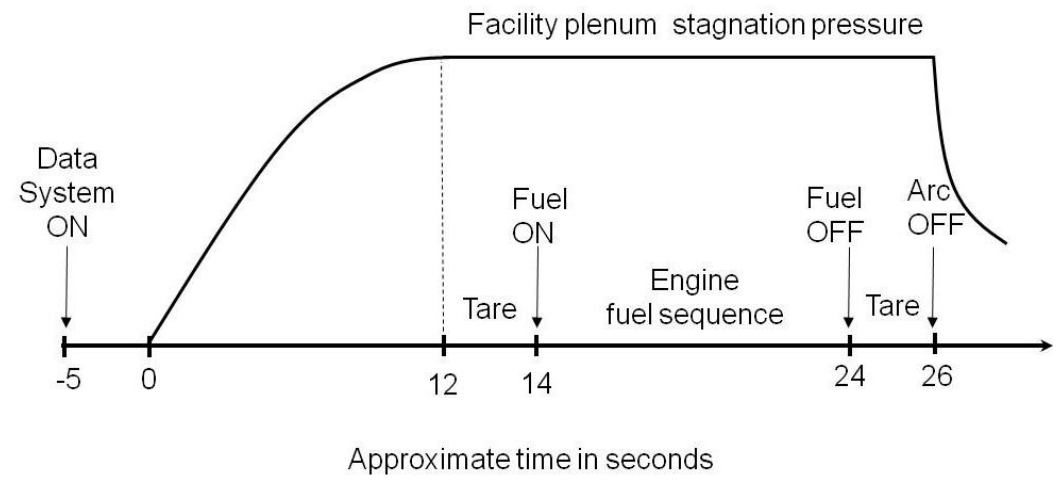

Figure 5. Typical HDCR run timeline. 

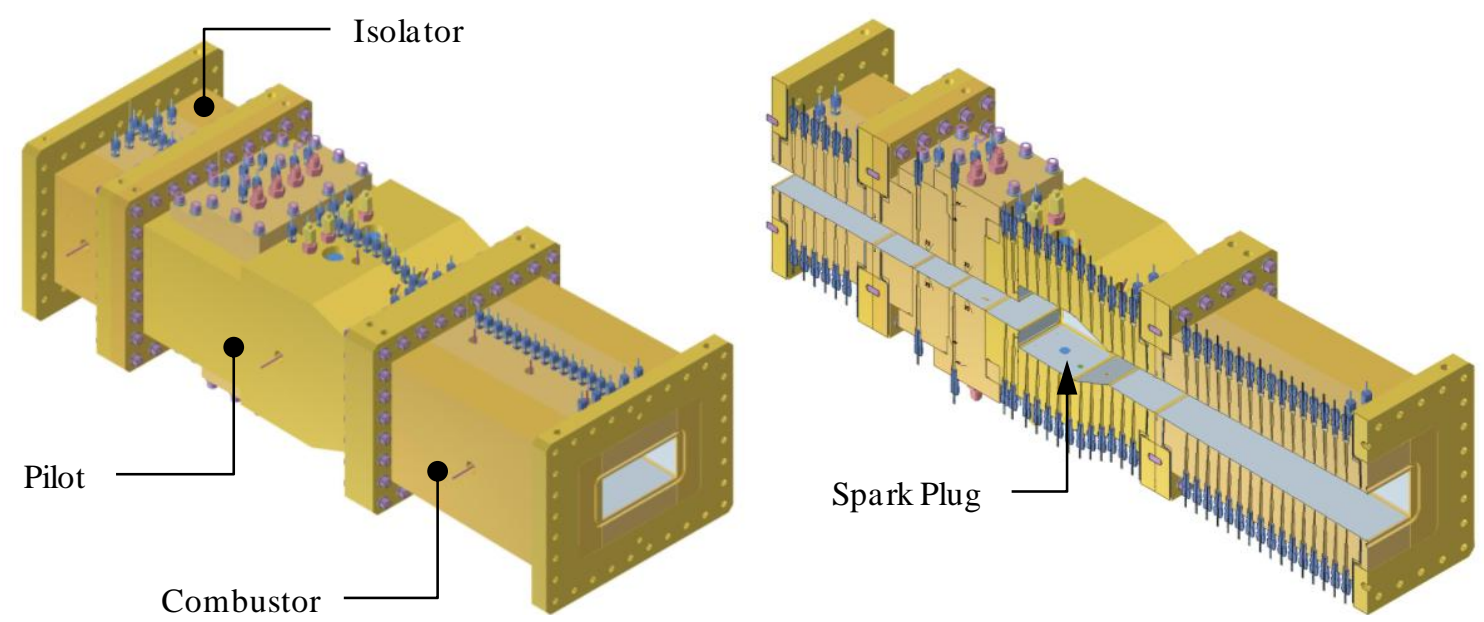

Figure 6. HDCR with centerline cut view.

of 1.9 inches. The flowpath surfaces are coated with a 0.025 inch thick zirconia thermal barrier coating (TBC) to extend the maximum run time and cycle life of the rig. Although the flowpath is symmetric, the upper flowpath surface, as installed in the test section, was arbitrarily chosen to be called the "body side", and the lower surface the "cowl side".

For the Mach 8 test series, the P1 injectors ( $x=9.6$ inches) and S1 injectors ( $x=16.5$ inches) were employed. The CI injectors ( $x=11.9$ inches) were also used, but only for ignition. For the remainder of this report, the P1 injectors are referred to as the primary injectors (denoted as "pri" or "P1"), the S1 injectors are referred to as the secondary injectors (denoted as "sec" or "S1") and the cavity injectors are referred to as cavity injectors (denoted as "cav" or "CI"). At each axial fuel injection station, there are four injector holes on the body side, fed from a dedicated fuel manifold, and four injector holes on the cowl side, fed from a separate dedicated manifold, for a total of eight injection holes per station. Each injector hole is spaced equally across the width of the flowpath. The injector holes on the body side directly oppose those on the cowl side. The primary injectors are 0.125 inch diameter circular holes which are canted at 15 degrees relative to the flowpath surface. The cavity injectors are 0.063 inch diameter circular holes directed normal to the flowpath surface and the secondary injectors are 0.094 inch diameter circular holes, also directed normal to the flowpath surface. Four spark plugs are located within the cavity to aid ignition and flameholding. Two spark plugs are on the body side, and two are on the cowl side, just downstream of the cavity fuel injection ports. These are identified in Figure 6.

The HDCR has a similar instrumentation layout to the flight test payload ${ }^{15}$ to ensure a direct comparison of results from flight to ground. The instrumentation consists of static pressure ports, heat flux gauges, and thermocouples. The layout of the instrumentation is shown in Figure 8. The rig contains 144 static pressure ports, 19 thermocouples, and four heat flux gauges. The pressure ports are 0.04 " in diameter and connected to ESP modules having ranges of $45,100,250$, and $750 \mathrm{psia}$. Centerline ports were spaced at 0.5 " intervals where possible. Spanwise ports are located at the 1.5", 6.9", 8.6", 11", and 26.5" axial stations, both body and cowl side.

Flowpath surface thermocouples are located on both body and cowl sides at axial stations 3", 11", 13.75", 14.5", 20.5", 23", and 26.5" along the flowpath, 0.75 " off-centerline towards the starboard. The body side

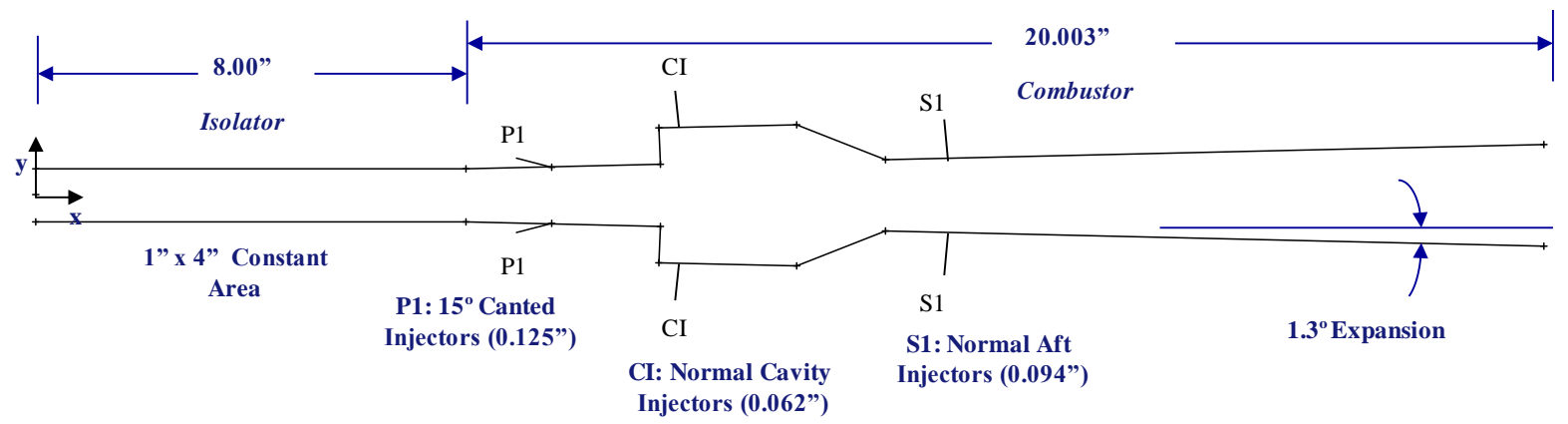

Figure 7. HDCR flowpath lines and fuel injection stations. 

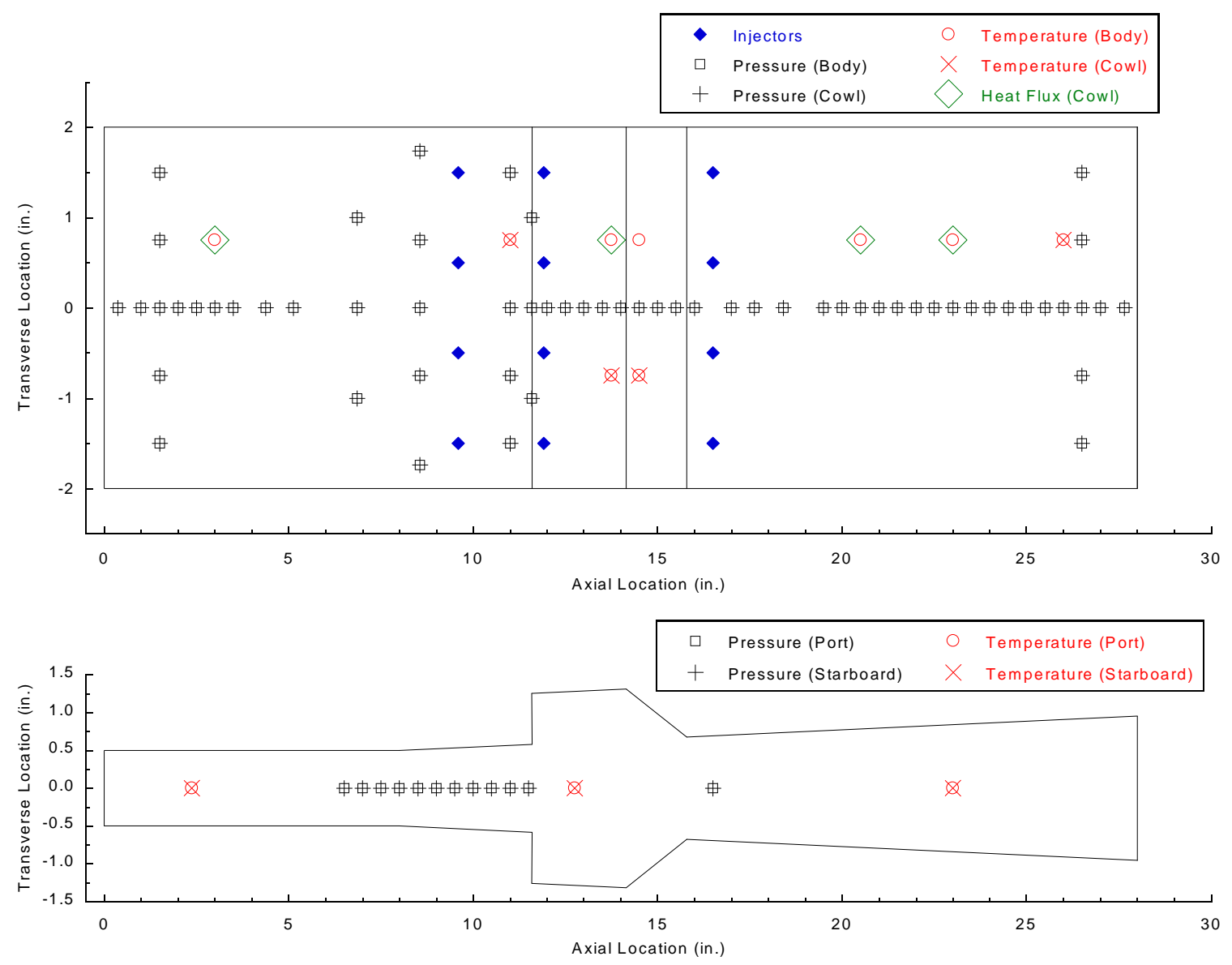

Figure 8. HDCR instrumentation layout.

thermocouples are zirconia TBC-coated and the cowl side thermocouples are uncoated in order to assess thermal loads modeling with TBC-coated hardware. There are also three thermocouples embedded within both the port and starboard walls at axial stations 2.38 ", 12.75 " and 23 " to assess heat loads to the sidewalls.

The heat flux gauges are located on the cowl side only, at the same axial stations as the thermocouples, and 0.75 " off-centerline to the port side of the flowpath. These locations were chosen intentionally to compare the heat loads measured to those computed from thermocouple data. All the units are water-cooled Gardon type gauges with a $500 \mathrm{Btu} / \mathrm{ft}^{2}$-s range. None of the heat flux gauges are coated with TBC. The thermocouple and heat flux measurements were used to provide wall boundary conditions for CFD analysis. A complete description of the thermal data analysis and scaling to flight conditions can be found in Ref.16.

\section{Test Conditions and Flight Simulation}

The goal of the HDCR ground simulation is to generate the isolator entrance flow properties corresponding to those in flight. In addition to the isolator entrance area, the parameters chosen to be matched were the onedimensionalized isolator entrance Mach number, static pressure, and stagnation enthalpy as predicted by CFD analyses for specific flight conditions. Flow features such as shocks from the forebody/inlet processing, boundary layer thickness, surface temperatures, and test gas composition are known differences between ground and flight. Although many studies have investigated the effects of nitric oxide on scramjet combustion, ${ }^{11,17,18}$ no correction for the presence of nitric oxide is made in this report; the fuel equivalence ratios quoted are calculated assuming the test gas has a molar composition of $21 \%$ oxygen, $78 \%$ nitrogen, and $1 \%$ Argon.

The facility nozzle employed for the Mach 8 test series has an exit Mach number of 3.51, as computed from two-dimensional equilibrium viscous CFD of the as-designed geometry, with a small correction for an as-built vs asdesigned difference in throat area. This is equal to the one-dimensionalized isolator entrance Mach number for Mach 8 flight, as calculated from flight inlet CFD analysis. ${ }^{19}$ Tests were conducted at two target conditions, corresponding 
to Mach 7.5 and 8.0 flight enthalpies, both at the maximum facility operating stagnation pressure of 625 psia. The conditions are summarized in Table 2, where $H_{t}$ and $P_{t}$ are the facility plenum stagnation enthalpy and pressure, respectively. The simulated flight Mach number $\left(M_{\infty}\right)$ corresponding to the stagnation enthalpy and the simulated flight dynamic pressure $\left(q_{\infty}\right)$ are also included in the table. For the Mach 8 flight simulation, the simulated flight dynamic pressure was determined by first computing the HDCR isolator entrance static pressure given the facility stagnation pressure and the CFD based nozzle exit static-to-stagnation pressure ratio. Then the simulated freestream dynamic pressure was determined by simply scaling the Mach 8 flight dynamic pressure by the ratio of ground to flight isolator entrance pressure (again, a one-dimensionalized value from flight CFD). Due to the facility stagnation pressure limitation, the dynamic pressure simulation is limited to 1015 psf compared dynamic pressure of 1910 psf for the nominal Mach 8 flight trajectory. A simulated flight dynamic pressure is not quoted for the Mach 7.5 enthalpy condition because the isolator entrance Mach number is consistent with Mach 8 and not Mach 7.5, therefore it does not represent an achievable flight condition.

Table 2. HDCR test conditions with the Mach 8 nozzle; nozzle exit Mach $=3.51$.

\begin{tabular}{l|c|c|c|c}
\hline \hline \multicolumn{1}{c|}{ Condition } & $\mathbf{H}_{\mathbf{t}}\left(\mathbf{B t u} / \mathbf{l b}_{\mathbf{m}}\right)$ & $\mathbf{P}_{\mathbf{t}}(\mathbf{p s i a})$ & $\mathbf{M}_{\infty}$ & $\mathbf{q}_{\infty}(\mathbf{p s f})$ \\
\hline $8 \mathrm{a}-$ baseline & 1293 & 625 & 8.0 & 1015 \\
\hline $8 \mathrm{~b}$ & 1173 & 625 & 7.5 & -- \\
\hline \hline
\end{tabular}

\section{Experimental Results}

A total of 16 successful, full-duration, fueled tests were conducted in the Phase I, Mach 8 test series. All of these tests were run with the JP-7 surrogate fuel mixture of ethylene and methane. Figure 9 is a summary of the experimental results obtained over the range of primary and secondary fuel injection splits tested and demonstrates the engine operability under simulated Mach 8 conditions. Ignition fuel splits, which included cavity injection, are not shown because ignition at Mach 8 is not relevant to flight. The symbols represent steady state fueling levels achieved and the shaded arrows indicate fuel levels through which the fuel was slowly ramped. For the HF2 Project, dual-mode operation is defined by a combustion-induced pressure rise upstream of the primary fuel injection site and scramjet-mode operation is defined by minimal combustion-induced pressure rise upstream of the primary fuel injection site and supersonic combusting flow (specifically, a one-dimensional combustor Mach number greater than one). Based on these definitions, Figure 9 indicates the fuel splits which yielded unacceptable, dual-mode operation and those which were scramjet-mode candidates (i.e., the combustion-induced pressure rise was downstream of the primary fuel injection, but analysis is required to determine if these fuel splits meet the supersonic part of the

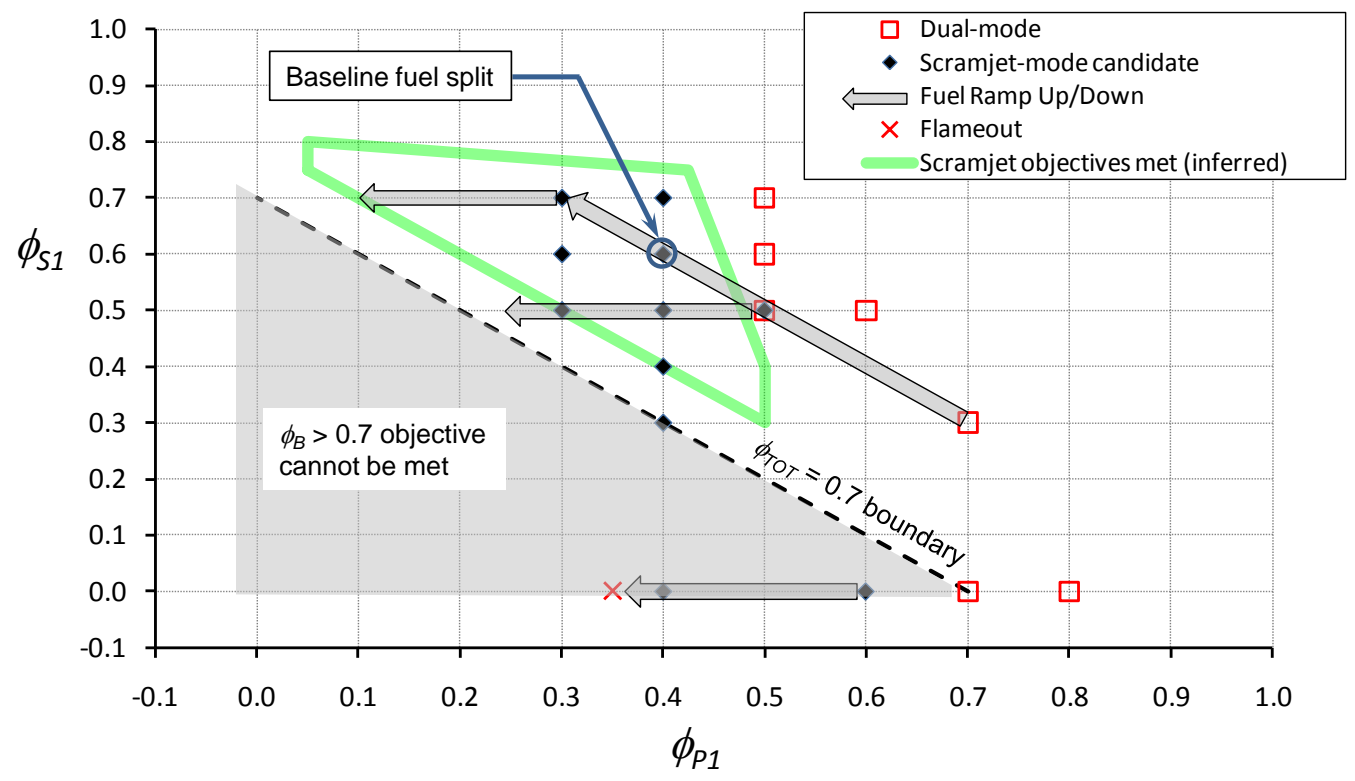

Figure 9. Mach 8 ground test result summary. 
definition). Below the dashed line, the total fuel equivalence ratio $\left(\phi_{\mathrm{TOT}}=\phi_{P I}+\phi_{S I}\right)$ is less than 0.7 and thus, $\phi_{B}>0.7$ is impossible. The area inside the green line represents a region expected to meet the objectives of scramjetmode operation with $\phi_{B}>0.7$. Because combustion efficiency will be less than $100 \%$, the $\phi_{T O T}=0.7$ line cannot be the lower boundary of this region. Thus, the region bounded by the green line is separated from the $\phi_{T O T}=0.7$ line by a representative combustion efficiency of $88 \%$. This value is reasonable given the data analysis results included in this paper. Pressure distributions and flowpath analysis which helped to identify the baseline fuel split of $\phi_{P I / S I}=0.4 / 0.6$ will be presented under the upcoming fueled results and flowpath analysis sections of this paper.

\section{A. Inflow}

It is necessary to understand the inflow to the combustor prior to interpreting fueled test results. The isolator wall pressures can be inspected to determine the quality of the combustor inflow. Figure 10 shows experimental isolator tare pressure distributions from a representative Mach 8 test (Run136.3). Body and cowl side centerline data is shown as well as sidewall data. Shown for comparison is the body/cowl centerline tare surface pressure distribution from three-dimensional VULCAN CFD analysis at Run 136.3 test conditions. ${ }^{10}$ (Note: In all the pressure distributions presented in this report, the pressures have been linearly scaled to the baseline facility stagnation pressure of 625 psia, to account for run-to-run and during-run variations in facility stagnation pressure). The CFD shows the expected pressure distrubution for this constant area isolator with uniform inflow. The pressure slightly increases due to boundary layer growth. The experimental pressure distribution shows some nonuniformities such as the high body side wall pressures at the isolator entrance, and the dip in pressure on both sides at the 3.5 inch axial station. These features are as yet unexplained. However, a more significant difference is that the CFD generally overpredicts the experimental pressures by roughly $30 \%$. This offset is thought to be partly due to thermal non-equlibrium, not modeled in the CFD, and partly due to a discrepancy between the as-analyzed vs astested nozzle throat area. The effects of thermal-non equilibrium were investigated with 3-dimensional viscous CFD analysis of the supersonic portion of the nozzle flow, using the LAURA code. ${ }^{20,21}$ In this analysis the vibrational energy mode was frozen at the throat level and results yielded a nozzle exit static pressure which was about $23 \%$ lower than that for thermal equilibruim analysis employed in VULCAN. The throat area discrepancy is a result of the fact that the CFD analysis used the as-designed nozzle geometry, but the as-measured throat area was about $6 \%$ smaller, thus it had a larger expansion ratio. One-dimensional thermally perfect gas analysis predicts that this will lower the exit static pressure by about $8 \%$. Together, these analyses could explain the observed $30 \%$ offset.

\section{B. Fueled Results and Operability}

All fueled tests were conducted with the surrogate fuel mixture and the spark plugs on (in contrast to the Mach 6 tests which were conducted with both ethylene fuel and the surrogate fuel mixture and with and without the use of spark plugs ${ }^{9}$ ). Early testing revealed that ignition with primary fuel only could not be achieved; however, it could be

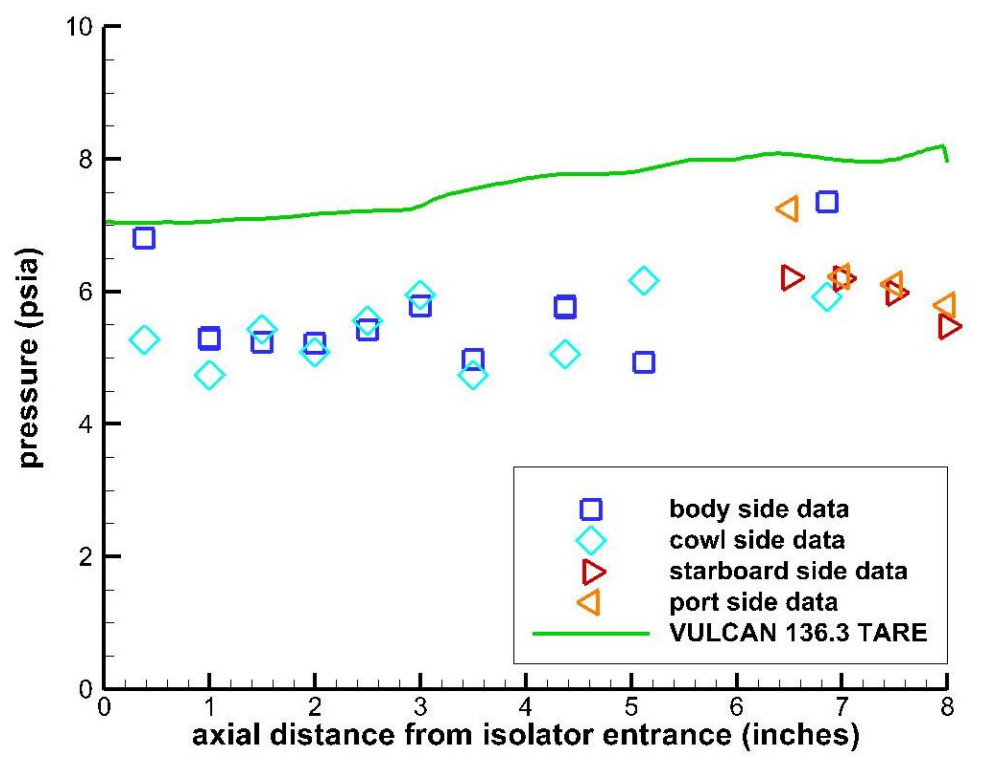

Figure 10. Comparison of experimental and CFD-calculated pressure distributions. 
achieved if a small amount of cavity fuel injection was added. Furthemore, combustion was sustained after turning the cavity injection off. Because the manner in which ignition was achieved was not important for the Mach 8 ground tests (since in flight, ignition would occur around Mach 6), once a successful igniton sequence was identified, it was employed for all remaining tests. An example fuel sequence is shown in Figure 11. In this sequence, fueling begins at $t=6$ seconds which is approximately 2 seconds after the facility reaches the target test conditions. As shown, a small amount of fuel $\left(\phi_{C I}=0.1\right)$ is injected from the cavity. Simultaneously, fuel is injected from the primary injection site at $\phi_{P I}=0.7$. Cavity injection is then reduced to zero and the primary and secondary fuel levels are programmed to their target schedules. In this example, the primary injection fuel equivalence ratio is held constant while the secondary is stepped up from 0.3 to 0.7 in increments of 0.1. Each step has about 2 seconds of dwell time to ensure the fuel levels and engine operation reached steady state. The data were examined at several time slices along steady fueling steps to gain an understanding of the stability of the isolator margin and peak pressure levels.

Experimental flowpath pressures corresponding to the steady state fueling levels of Figure 11 are shown in Figure 12. Tare pressure data and rig geometry are shown on all plots for reference. Also, the locations of the primary (P1) and secondary (S1) injectors are indicated on the figure by vertical, dashed lines. Figure 12a shows pressure distributions for the ignition fuel split of $\phi_{P I / C I}=0.7 / 0.1$ as well as for primary/secondary combinations of $\phi_{P I / S I}=0.4 / 0,0.4 / 0.3$, and $0.4 / 0.4$ after the cavity fuel is turned off. Figure $12 \mathrm{~b}$ shows data for subsequent fuel splits of $\phi_{P I / S I}=0.4 / 0.5,0.4 / 0.6$, and $0.4 / 0.7$. It is interesting to note that the ignition fuel split yields robust combustion in the cavity region, but weak combustion downstream of the cavity and it is clearly not a candidate for scramjet-mode operation due to the extent of the combustion-induced pressure rise in the isolator. However, as explained, this fuel split was only necessary to achieve ignition at Mach 8 in the ground test and is of no consequence to the flight fuel sequence. The remainder of fuel splits shown, however, were potentially viable fuel spits. In some cases, a range of distinctly different pressure distributions were obtained at a fixed fueling level. In these cases, two time slices are shown in the plots (solid and dashed lines) which bound the range of pressures observed during that fueling level. However, in all cases, pressure rise does not move forward of the primary injector location, thus all fuel splits satisfy this part of the scramjet-mode definition (flowpath analysis is required to determine if they satisfy the requirement that the one-dimensional Mach number remains greater than one throughout the combustor). As the secondary fueling level increases up to $\phi_{S I}=0.5$, there is an increase in downstream combustor pressures. Further increases in secondary fueling have little effect. Thus, the fueling splits with a secondary level of $\phi_{S I}=0.5$ or greater, which all show a similar range of pressure distributions, were deemed the best candidates for meeting the performance objective of $\phi_{\mathrm{B}}>0.7$.

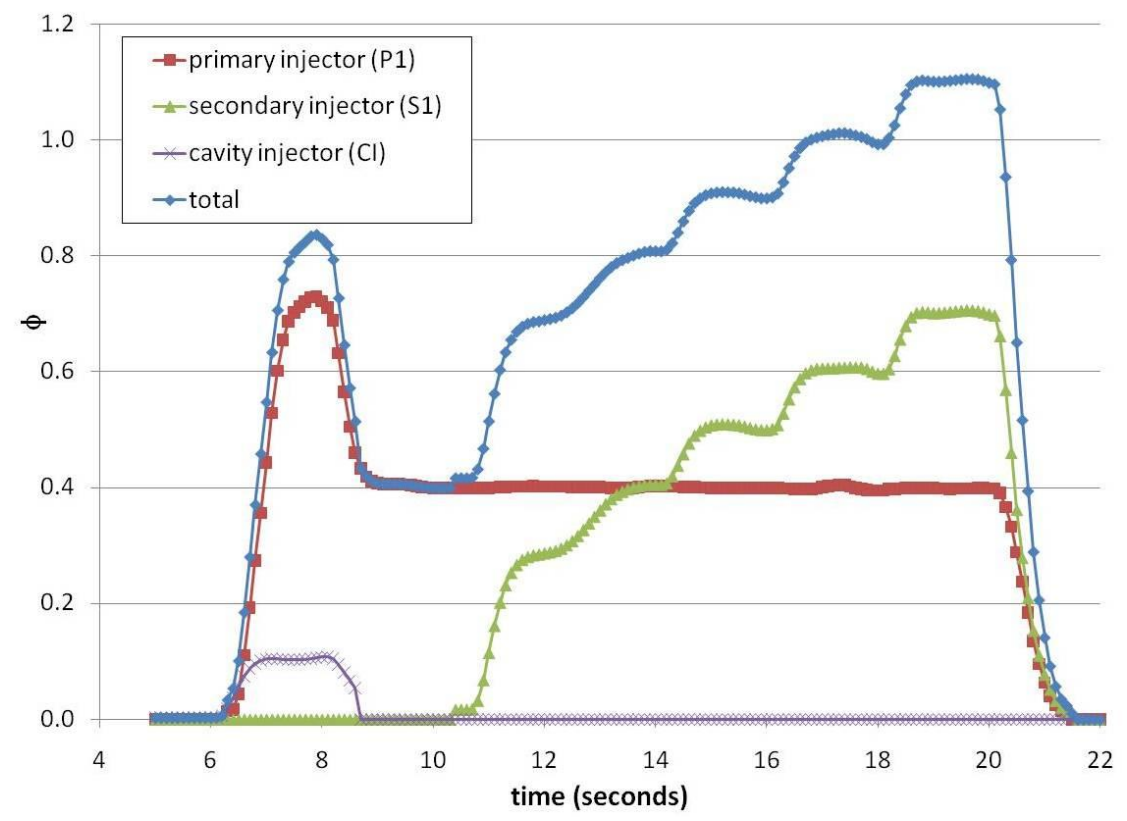

Figure 11. Fuel schedule for Mach 8, Run 136.3. 


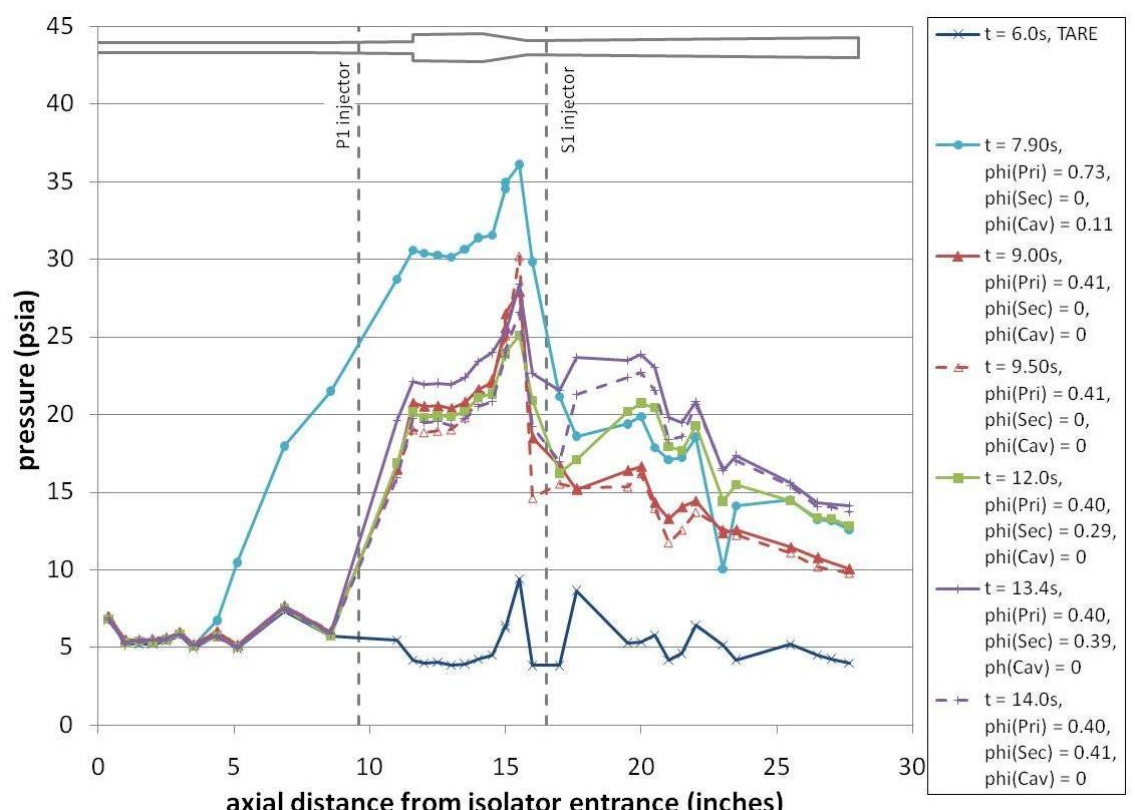

(a)

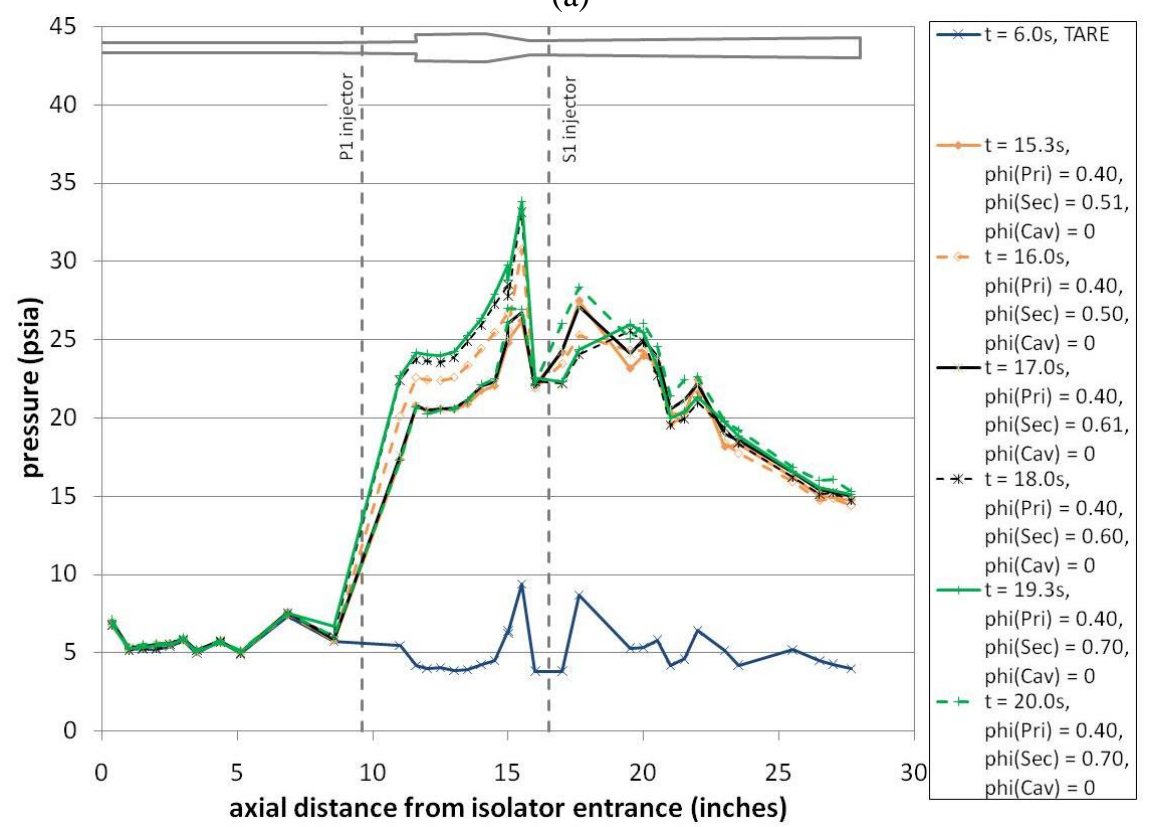

(b)

Figure 12. Body side centerline pressure data for Mach 8, Run 136.3.

In order to determine the margins available for the flight fuel control system, the sensitivity of the flowpath operation to variations in both the primary and secondary fueling levels was assessed. Because a fuel split of $\phi_{P I / S I}=0.4 / 0.6$ had been preliminarily selected as a candidate fuel split for Mach 8, sensitivities about this fuel split were investigated. Figure 13 and Figure 14 illustrate the sensitivity to primary fueling and secondary fueling, respectively. Also in these plots, both body and cowl side centerline pressure data are presented to show that body and cowl side pressure distributions were nearly identical; therefore, only body side distributions are shown in all other plots. Figure 13 shows pressure distributions with secondary fueling held constant at $\phi_{S I}=0.6$ while primary fueling increased from $\phi_{P I}=0.3$ to 0.5 . Figure 14 shows pressure distributions with primary fueling held constant at $\phi_{P I}=0.4$ while secondary fueling increased from $\phi_{S I}=0.5$ to 0.7 (a repeat of fuel splits from Figure 12b). Over the range of fuel levels investigated, the flowpath operation is clearly very sensitive to primary fuel injection. Relative 
to the $\phi_{P I / S I}=0.4 / 0.6$ fuel split, increasing the primary fuel by $25 \%$ significantly increases the cavity/peak pressures and pushes the combustion-induced pressure rise forward of the primary injection site. Thus, at a fuel split of $\phi_{P I / S I}=0.4 / 0.6$, the margin available for increasing the primary $\phi$ is less than $25 \%$. HDCR Phase II test plans include defining this margin more precisely. In contrast, varying the secondary fuel by $\pm 15 \%$ relative to a fuel split of $\phi_{P I / S I}=0.4 / 0.6$ had very little effect on combustor operation, thus there is ample margin available relative to secondary fueling.

To further understand the operability limits of the HDCR, flameholding tests were conducted. Three tests were conducted in which the secondary fuel was held constant while the primary fuel was slowly ramped down (see the horizontal gray arrows in Figure 9). Body side centerline pressures from two such tests are shown in Figure 15 and Figure 16. In Figure 15, secondary fuel is held constant at $\phi_{S I}=0.5$ while primary is ramped down from $\phi_{P I}=0.6$ to

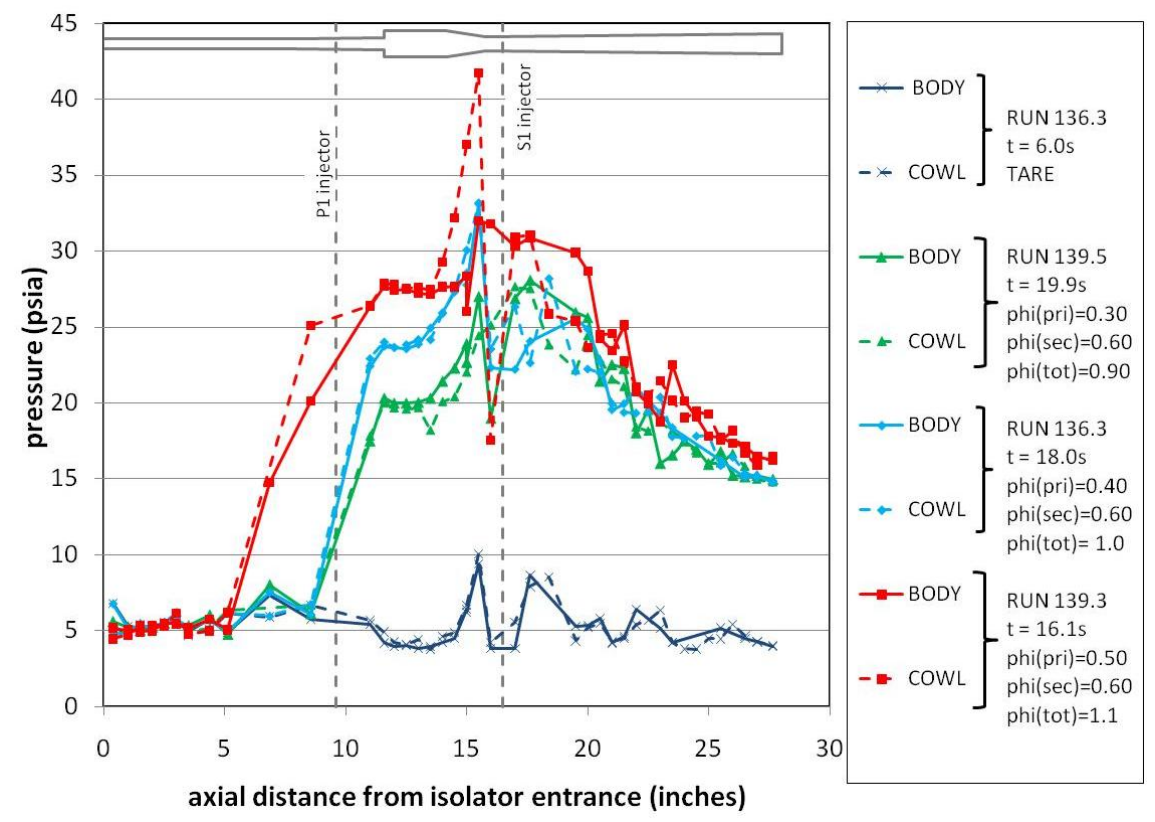

Figure 13. Body and cowl side centerline pressure data indicating sensitivity to primary fueling variations.

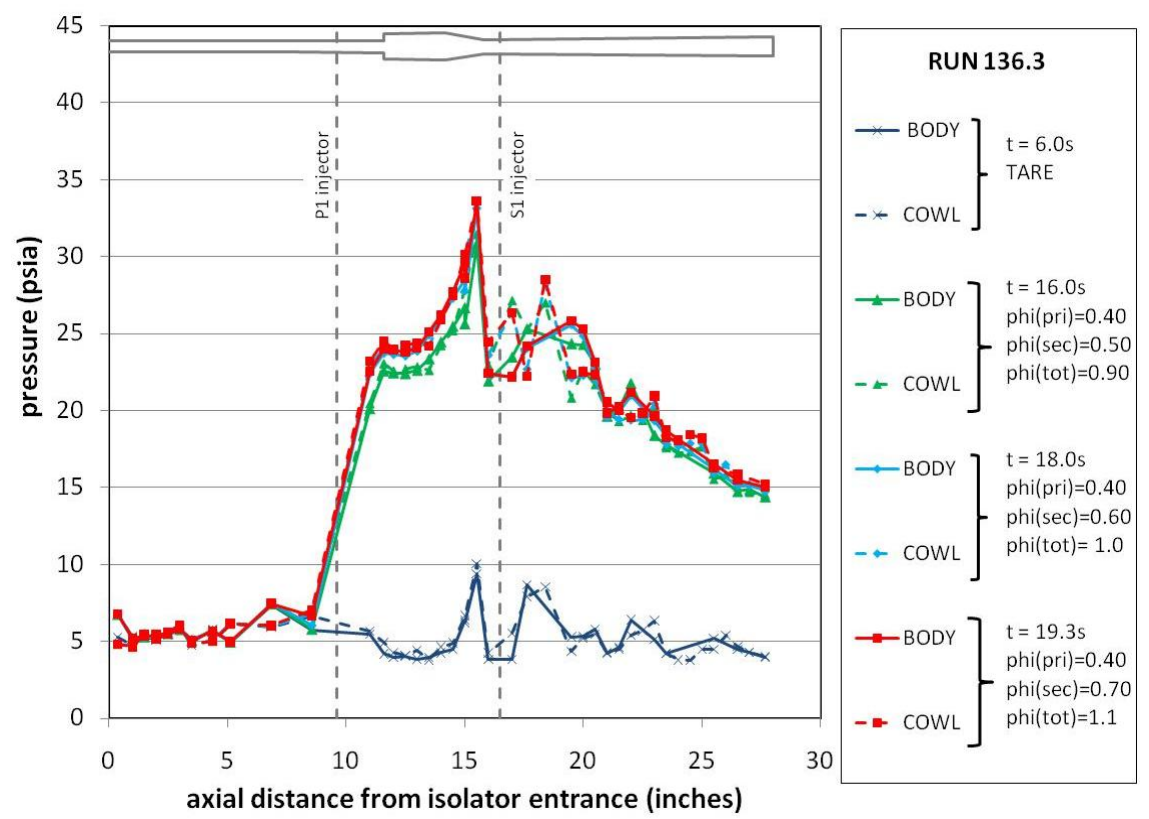

Figure 14. Body and cowl side centerline pressure data indicating sensitivity to secondary fueling variations. 
0.25 and in Figure 16, secondary fuel is held constant at $\phi_{S I}=0.7$ while primary is ramped from $\phi_{P I}=0.3$ to approximately zero. Pressure distributions are shown at selected times during the ramp down until the minimum measureable fuel level was reached. A flameout is indicated by a reduction in combustor pressures to nearly tare levels. As shown, with a secondary fuel level of $\phi_{S I}=0.5$, primary was reduced to $\phi_{P I}=0.25$ with no flameout. At a higher $\phi_{S I}=0.7$, primary was reduced to as low as $\phi_{P I}=0.1$ with no flameout. Although there was a substantial drop in cavity pressures, downstream combustion was sustained.

In flight, the combustor must transition from dual-mode to scramjet-mode at some point in the Mach 6 to $8+$ trajectory. Because a fuel split of $\phi_{P I / S 1}=0.4 / 0.6$ had been identified in the HDCR Mach 6 test series as having acceptable dual-mode operation at Mach 6.5 enthalpy, ${ }^{9}$ it was of particular interest at Mach 8 as it offered the benefit of a fixed ratio of primary to secondary fuel level from dual-mode to scramjet-mode, thus simplifying the flight fuel system configuration. Results presented thus far show that this fuel split had acceptable margin with respect to

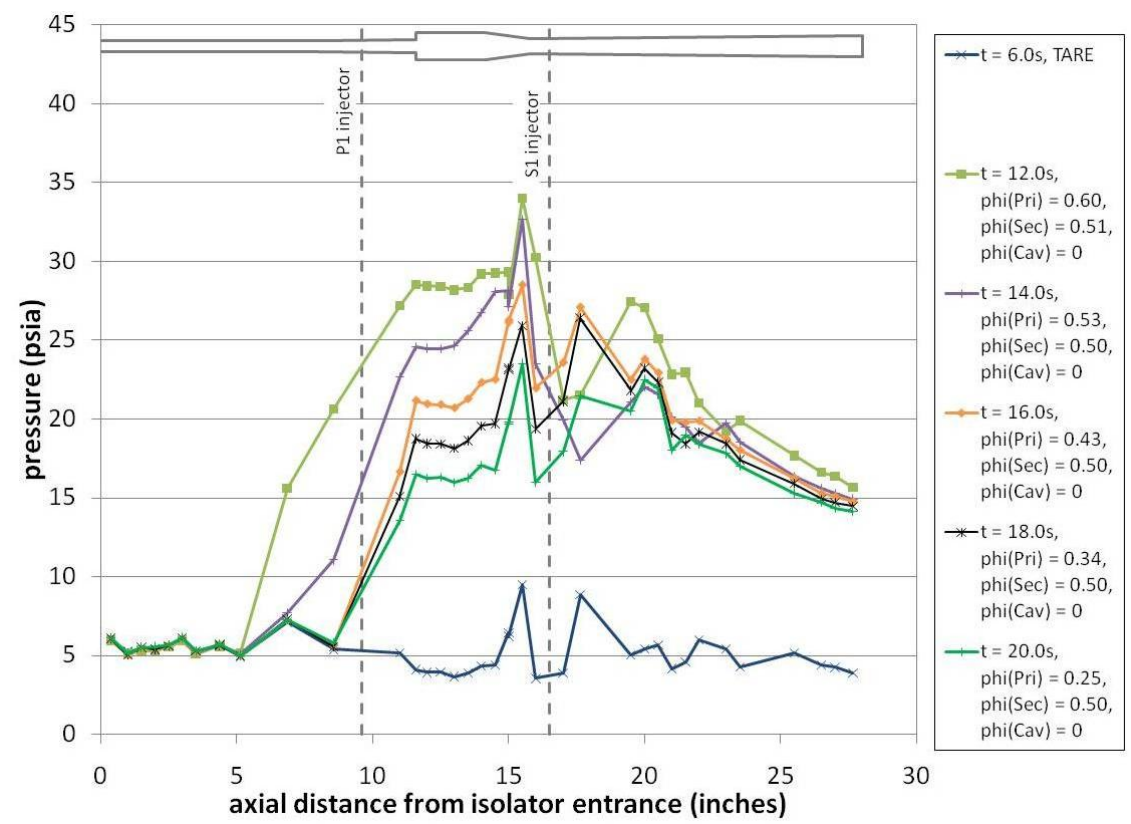

Figure 15. Pressure distributions from a flameholding test with $\phi_{\mathrm{S} 1}=0.5$, Run 136.4.

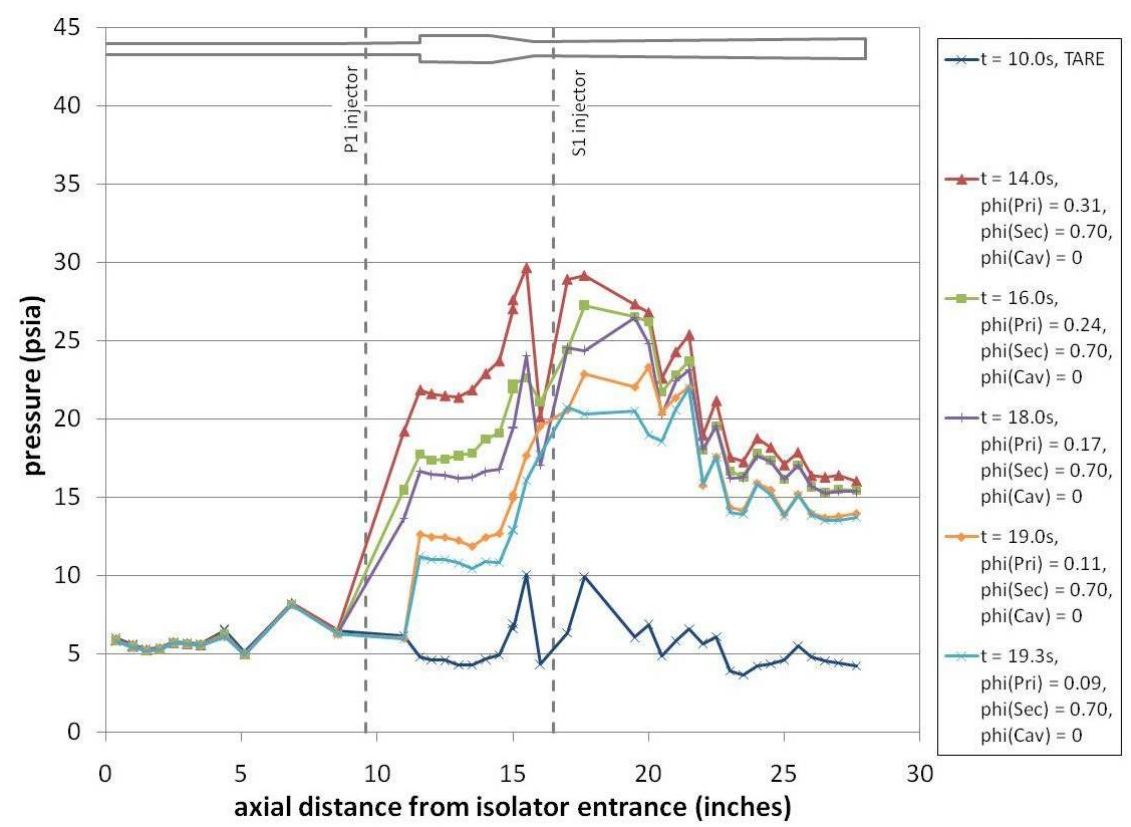

Figure 16. Pressure distributions from a flameholding test with $\phi_{\mathrm{S1}}=0.7$, Run 139.6. 
variations in primary and secondary fuel that would still maintain the combustion-induced pressure rise downstream of the primary injection site, as well as acceptable margin relative to a flameout limit. Figure 17 is a plot of several tests with the 0.4/0.6 fuel split. The results are repeatable in both the forward extent of the combustion-induced pressure rise (part of the scramjet-mode definition) and in the pressure levels downstream of the cavity (which are a good indication of combustion efficiency). Although some variation exists in the peak combustor pressure, it is not expected to be substantial enough to change the engine operating mode or the performance. Therefore, this fuel split became the candidate for Mach 8 flowpath analysis (shown in the next section) to determine if it met the scramjet mode requirement of combustor $M_{I D}>1$ and the performance requirement of $\phi_{B}>0.7$.

A portion of the Mach 8 test series also included simulations at Mach 7.5 enthalpy (Condition $8 \mathrm{~b}$ from Table 2) to investigate the sensitivity of the combustor operation to total enthalpy/flight condition. Similar to the approach at Mach 8 enthalpy, fuel schedules similar to that of Figure 11 were exercised to find a fuel split that would satisfy the scramjet operating mode definition followed by examinations of flameholding and sensitivity to primary and secondary fueling. Although a majority of these data are not presented here, the important results are that 1) a fuel split of $\phi_{P I S I}=0.3 / 0.7$ showed scramjet-mode operation and was selected for analysis and 2) scramjet-mode operation was not achieved with a $\phi_{P I / S I}=0.4 / 0.6$ fuel split. This is shown in Figure 18 where the pressure distributions for Mach 8 and 7.5 enthalpies are compared for $\phi_{P I / S I}=0.4 / 0.6$. For the Mach 7.5 enthalpy simulation, the isolator pressure rise begins upstream of the primary fuel injection site. The implication from these data is that the flight engine may still be operating in dual-mode at Mach 7.5. This emphasizes the need for the flight trajectory to comfortably reach Mach 8+ in order to meet the flight objectives. As shown in Figure 2, the nominal flight trajectory is expected to enable testing up to about Mach 8.4. The fuel schedule has been designed to continue fueling at constant conditions beyond Mach 8.0 Together, these should ensure adequate margin (with respect to freestream Mach number) for achieving scramjet-mode operation during the flight experiment.

\section{Combustor Performance Verification}

At the completion of Phase 1 HDCR testing, a baseline data set from each simulated flight enthalpy was chosen for benchmarking analysis tools and for verification of flowpath operatating mode and performance. At Mach 8, this data set was Run 136.3, $t=18.0$ s (see Figure 11 through Figure 17). As stated previously, the science objectives for Mach 8 flight are to achieve scramjet-mode operation and a burned fuel equivalence ratio of 0.70 or greater. To verify these objectives could be met, three-dimensional CFD was used. VULCAN and CFD++ computational codes were utilized. A complete discussion of the analysis using these codes (including the one-dimensionlization methods and combustion efficiency calculations) can be found in Ref. 10. However, selected results are highlighted here.

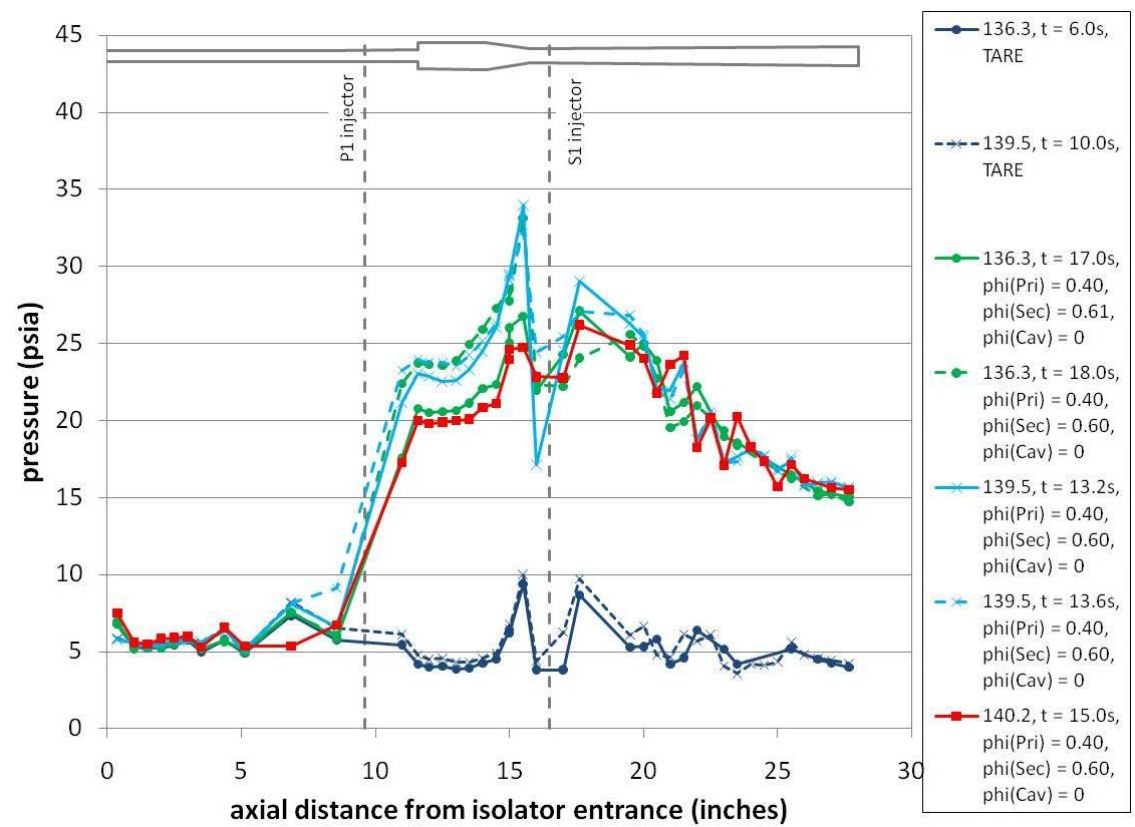

Figure 17. Repeatability of Mach 8 operation at nominal I fuel split 


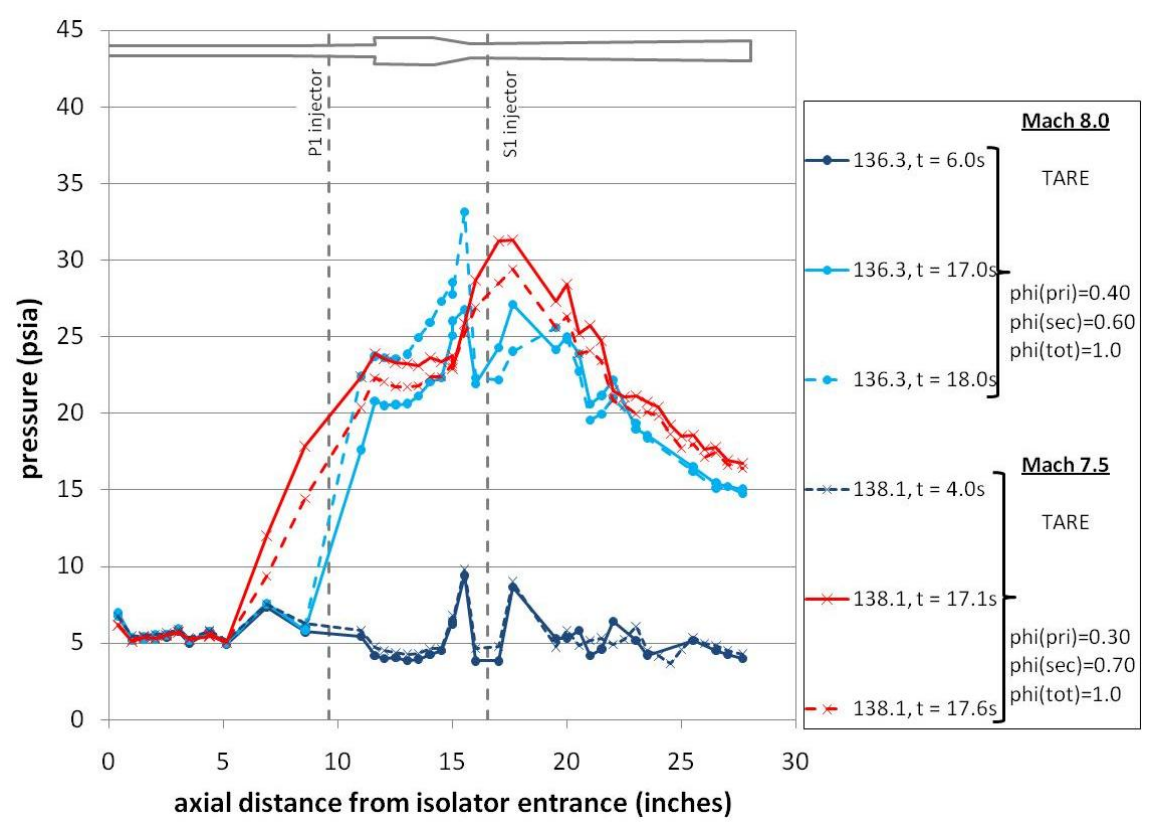

Figure 18. Mach 8.0 and Mach 7.5 enthalpy comparison for $0.4 / 0.6$ fuel split.

Figure 19 is a plot of the Mach 8, Run 136.3 tare and fueled pressure data with the three-dimensional CFD simulation results at Run 136.3 run conditions. Both CFD solutions match the data acceptably well, although the predicted location of the isolator pressure rise is off by about one duct height. To confirm that the engine is operating in scramjet-mode, two criteria must be met: 1) significant pressure rise must not occur upstream of the primary fuel injection location and 2) the calculated one-dimensional Mach number must be supersonic throughout the flowpath. These criteria were adopted by the HIFiRE Flight 2 project team at the start of this effort. As shown in Figure 19, both CFD solutions show that no significant pressure rise occurs upstream of the primary injector location. The calculated one-dimensional Mach number for both CFD solutions is shown in Figure 20. Both solutions predict that the one-dimensional Mach number is supersonic throughout the flowpath (differences between the results are largely due to different one-dimensionalization methods employed by the two codes). Together, the results in Figure 19 and Figure 20 confirm that the HDCR is running in scramjet-mode during Mach 8 operation.

Because the CFD solutions closely match the HDCR pressure distribution throughout the combustor (and wall pressure is directly related to the amount of heat released by the fuel that is burned), the CFD calculations should provide an excellent approximation of the engine combustion efficiency (although the combustion efficiency derived from CFD++ will be conservatively low due to poorer agreement with the data downstream of $x=18$ inches). Table 3 contains the resulting combustion efficiencies derived from the CFD solutions for the Mach 7.5 and 8.0 simulated flight enthalpy cases. The large difference in combustion efficiency predicted by the two codes is due to different chemical kinetics models employed, which results in a lower combustion heat release and lower wall pressures in the CFD++ solutions. As mentioned, more complete discussion of the analysis is presented elsewhere ${ }^{10}$ However, in both cases, a scramjet-mode burned fuel equivalence ratio greater than 0.7 has been computed. The results also indicate that margin exists in achieving the science objectives although it is yet to be determined if this margin is sufficient for any uncertainties in the flight condition, fueling levels, or other unexpected in-flight phenomena.

The HDCR Mach 6 and Mach 8 ground test results and corresponding computational analysis indicate that a fuel split of $\phi_{P I / S I}=0.4 / 0.6$ could meet both the dual-mode and scramjet-mode objectives for the HiFIRE Flight 2. As a result, the flight fuel schedule shown in Figure 21 was developed. Fueling will begin at a Mach 6 flight condition and ramp up to the desired fuel split of $\phi_{P I / S 1}=0.4 / 0.6$ as the payload accelerates to Mach 6.5. From Mach 6.5 to Mach 8.5, the fuel split will be held constant while the changing flight test conditions are expected to drive the transition from dual-mode to scramjet-mode. The CFD tools, benchmarked with ground test data, will be used in flight simulations to confirm that this fuel schedule will meet the flight objectives. ${ }^{10}$ 


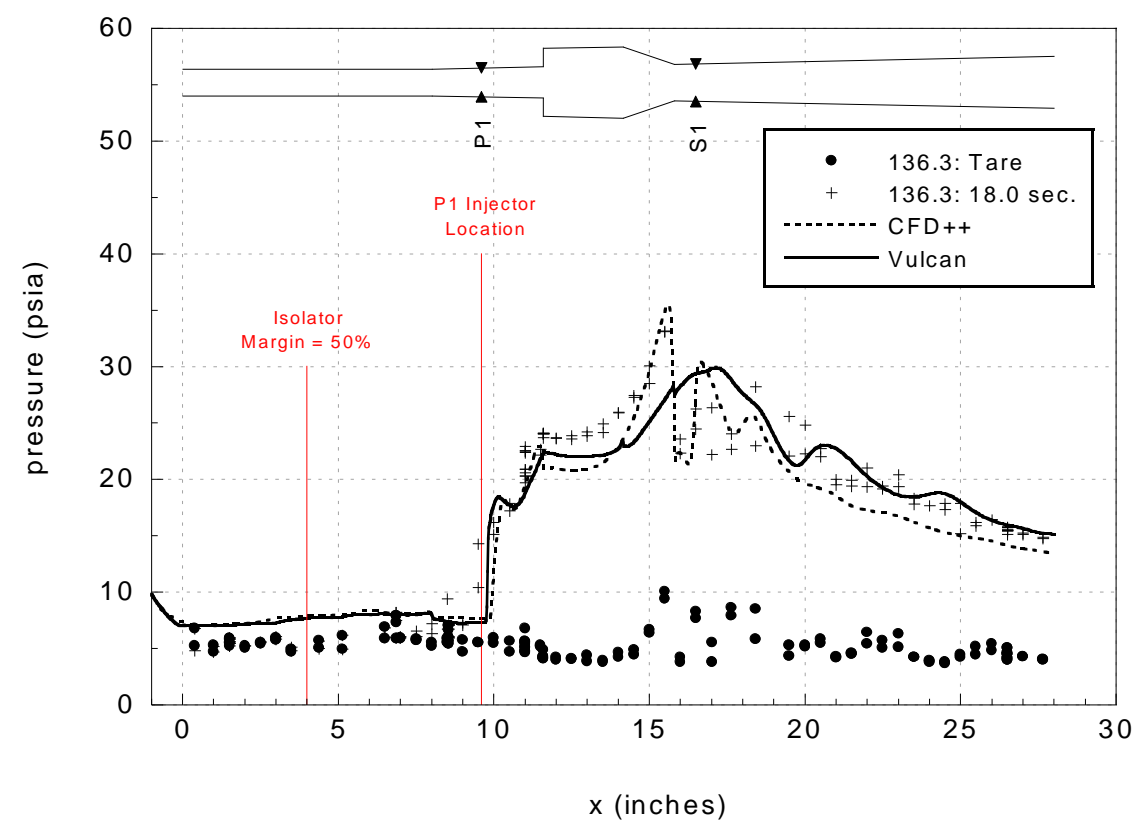

Figure 19. Mach 8 CFD modeling results, pressure versus axial location.

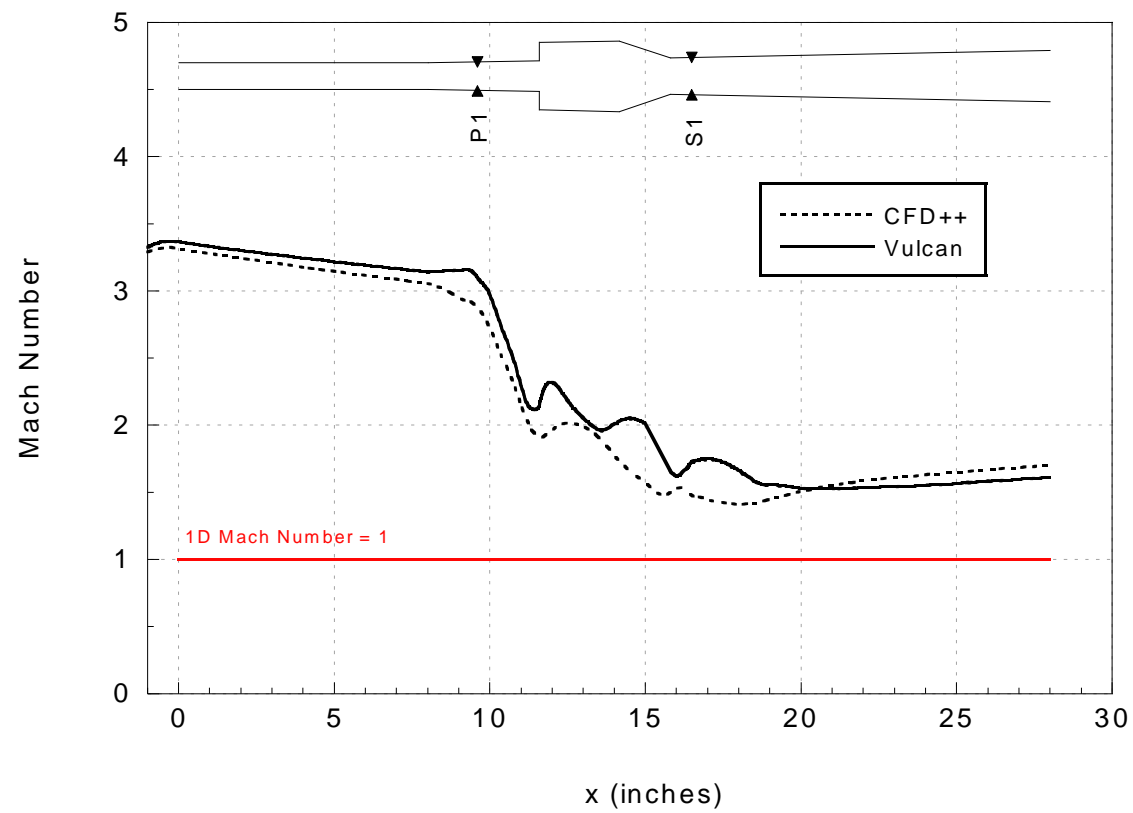

Figure 20. Mach 8 CFD modeling results, one-dimensional Mach number versus axial location.

Table 3. CFD-calculated combustion efficiency for Mach 7.5 and 8.0 baseline cases.

\begin{tabular}{c|c|c|c|c}
\hline \hline \multicolumn{2}{c|}{ Conditions } & \multicolumn{2}{c}{ Combustion Efficiency } \\
\hline Test Reference & $\phi_{\mathbf{P 1}}$ & $\boldsymbol{\phi}_{\mathbf{S} 1}$ & CFD++ & VULCAN \\
\hline Mach 7.5 (135.6, 19.0 s.) & 0.30 & 0.70 & $81.2 \%$ & $93.0 \%$ \\
\hline Mach 8.0 (136.3, 18.0 s.) & 0.40 & 0.60 & $83.6 \%$ & $93.0 \%$ \\
\hline \hline
\end{tabular}




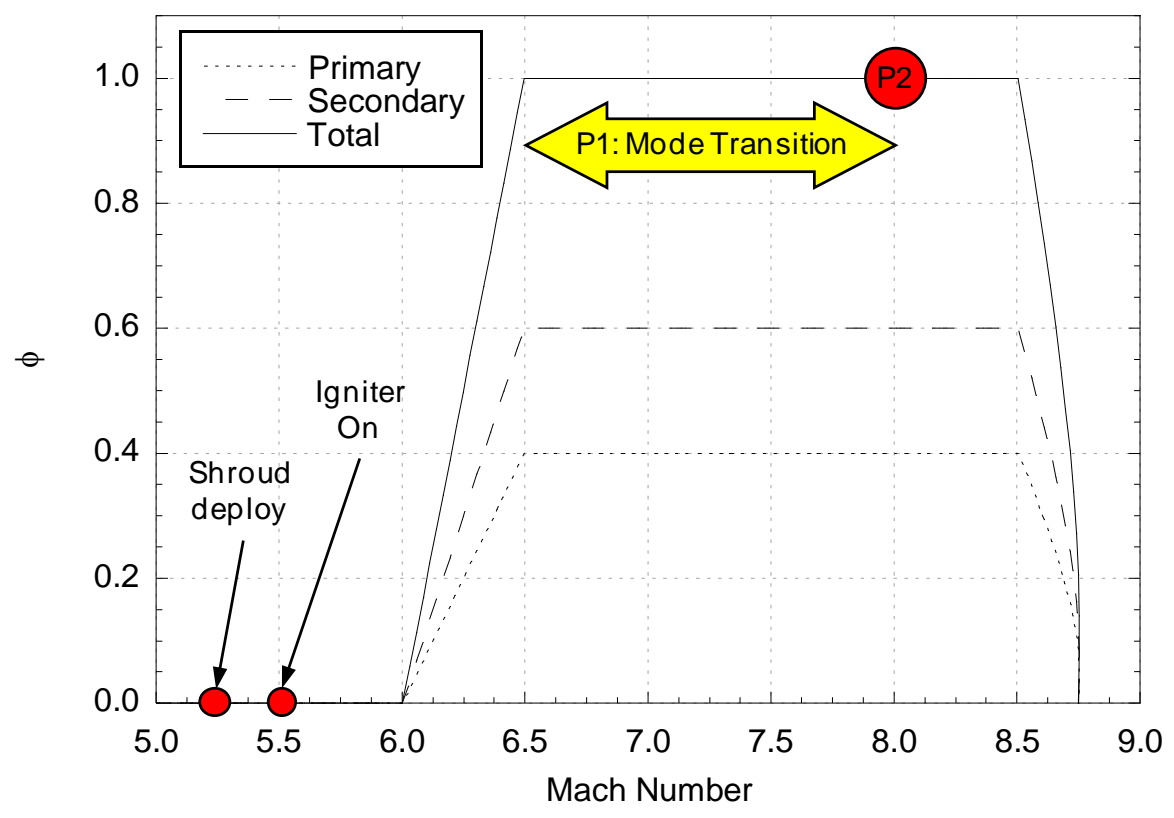

Figure 21. HIFiRE Flight 2 fuel schedule.

\section{Summary and Conclusions}

The completion of the Mach 8 tests concludes Phase I of the HDCR ground test program. The Mach 8 tests were successful in supporting several aspects of the HIFiRE Flight 2. First, a fuel split of $\phi_{P I / S I}=0.4 / 0.6$ was identified as a candidate fuel distribution for producing scramjet-mode operation. Second, variations in both primary and secondary fueling levels were explored to determine the fuel split margins available for a successful flight experiment. Third, the lean blow-out characteristics of the combustor were explored and show that there is a very wide fueling margin with respect to flameout. Finally, the tests provided data sets to be used for benchmarking the computational tools that will be used to predict flight performance. HDCR flowpath pressures were successfully matched by 3D CFD codes and accompanying analysis verified that the primary flight science objectives can be met using the ground test combustor flowpath geometry. Namely, the combustor operated in scramjet-mode, i.e., there was no significant pressure rise upstream of the primary injector and the calculated one-dimensional Mach number was greater than one throughout the flowpath. In addition, the combusted fuel equivalence ratio was calculated to be well above the required value of 0.70 . These benchmarked CFD codes will be used in pre- and post-flight analyses.

\section{Future Plans}

Phase II testing of the HDCR will begin in early 2011. The objectives of this phase are to refine the operability margins of the nominal fuel splits at Mach 6.5, 7.0, and 8.0. Additionally, a diode laser-based measurement system will be incorporated into the rig to demonstrate its operation. Post-test analysis tools will continue to be used to verify the operation and performance of the flowpath and refine the model used for flight predictions and postexperiment analyses.

\section{References}

${ }^{1}$ Dolvin, D. J., "Hypersonic International Flight Research and Experimentation," AIAA/DLR/DGLR $16^{\text {th }}$ International Space Planes and Hypersonic Systems and Technologies Conference, Bremen, Germany, AIAA Paper 2009-7228, October, 2009.

${ }^{2}$ Smart, M. K., Hass, N. E., and Paull, A., "Flight Data Analysis of the HYSHOT 2 Scramjet Flight Experiment," AIAA Journal of Propulsion and Power, Vol. 44, No. 10, October, 2006, pg. 2366-2375. 
${ }^{3}$ Walker, S. H., Rodgers, F. C., and Esposita, A. L., "Hypersonic Collaborative Australia/United States Experiment (HYCAUSE)," AIAA Paper 2005-3254, May 2005.

${ }^{4}$ Jackson, K., Gruber, M., and Buccellato, S., "HIFiRE Flight 2 Project Overview and Status 2011," presented at $17^{\text {th }}$ AIAA International Space Planes and Hypersonic Systems and Technologies Conference, San Francisco, CA, April 11-14, 2011.

${ }^{5}$ Jackson, K. R., Gruber, M. R., Barhorst, T. F., "The HIFiRE Flight 2 Experiment: An Overview and Status Update," 45 ${ }^{\text {th }}$ AIAA/ASME/SAE/ASEE Joint Propulsion Conference, AIAA Paper 2009-5029, August 2009.

${ }^{6}$ Jackson, K. R., Gruber, M. R., Jackson, T. A., and Hass, N. E., "HIFiRE F2 Scramjet Experiment Overview," 55th JANNAF Propulsion Meeting, Newton, MA, May, 2008.

${ }^{7}$ Pellett, G. L., Vaden, S. N., and Wilson, L. G., “Opposed Jet Burner Extinction Limits: Simple Mixed Hydrocarbon Fuels vs. Air,” AIAA Paper 2007-5664, July 2007.

${ }^{8}$ Ferlemann, P. G., "Forebody and Inlet Design for the HIFiRE F2 Flight Test," 55th JANNAF Propulsion Meeting, Newton, MA, May, 2008.

${ }^{9}$ Hass, N., Cabell, K., and Storch, A., "HIFiRE Direct Connect Rig (HDCR) Phase I Ground Tests Results from the NASA Langley Arc-Heated Scramjet Test Facility," JANNAF $43^{\text {rd }}$ CS $/ 31^{\text {st }}$ APS $/ 25^{\text {th }}$ PSHS Joint

Subcommittee Meeting, December, 2009, La Jolla, CA.

${ }^{10}$ Storch, A., Bynum, M., Liu, J., Gruber, M., Hass, N., and Cabell, K., "Combustor Operability and Performance Verification for HIFiRE Flight 2," presented at $17^{\text {th }}$ AIAA International Space Planes and Hypersonic Systems and Technologies Conference, San Francisco, CA, April 11-14, 2011.

${ }^{11}$ Cabell, K. F. and Rock, K.E., "A Finite Rate Chemical Analysis of Nitric Oxide Flow Contamination Effects on Scramjet Performance,” NASA TP-212159, May, 2003.

${ }^{12}$ Howard, R. P., Dietz, K. L., McGregor, W. K., and Limbaugh, C. C., "Nonintrusive Nitric Oxide Density Measurements in the NASA Langley Arc-Heated Scramjet Test Facility,” AEDC TR-90-29, 1991.

${ }^{13}$ Lemmon, E. W., Huber, M. L., McLindon, M. O., REFPROP - Reference Fluid Thermodynamic and Transport Properties, NIST Standard Reference Database 23, Version 8.0, 2007.

${ }^{14}$ Gruber, M. R., Jackson, K. R., Jackson, T. A., and Liu, J., "Hydrocarbon-Fueled Scramjet Combustor Flowpath Development for Mach 6-8 HIFiRE Flight Experiments," 55th JANNAF Propulsion Meeting, Newton, MA, May, 2008.

${ }^{15}$ Gruber, M., Barhorst, T. Jackson, K., Eklund, D., Hass, N., Storch, A., and Liu, J., "Instrumentation and Performance Analysis Plans for the HIFiRE Flight 2 Experiment," AIAA Paper 2009-5032, August 2009.

${ }^{16} \mathrm{Cuda}, \mathrm{V}$. and Hass, N., "Heat Flux and Wall Temperature Estimates for the NASA Langley HIFiRE Direct Connect Rig", JANNAF $43^{\text {rd }}$ CS / $31^{\text {st }}$ APS / $25^{\text {th }}$ PSHS Joint Subcommittee Meeting, December, 2009, La Jolla, CA.

${ }^{17}$ Lai, H. and Thomas, S., "Numerical Study of Contaminant Effects on Combustion of Hydrogen, Ethane and Methane in Air," AIAA Paper 95-6097, April 1995.

${ }^{18}$ Pellett, G. L., Dawson, L. C., Vaden, S. N., and Wilson, L. G., "Nitric Oxide and Oxygen-Air Contamination Effects on Extinction Limits of Non-premixed Hydrocarbon-Air Flames for a HIFiRE Scramjet," JANNAF $43{ }^{\text {rd }}$ CS / $31^{\text {st }}$ APS $/ 25^{\text {th }}$ PSHS Joint Subcommittee Meeting, December, 2009, La Jolla, CA.

${ }^{19}$ Gruber, M., Ferlemann, P. and McDaniel, K "HIFiRE Flight 2 Flowpath Design Update," JANNAF $43^{\text {rd }}$ CS / $31^{\text {st }}$ APS $/ 25^{\text {th }}$ PSHS Joint Subcommittee Meeting, December, 2009, La Jolla, CA.

${ }^{20}$ Gnoffo, P.A., "Upwind-Biased, Point-Implicit Relaxation Strategies for Viscous, Hypersonic Flows,” AIAA89-1972, June 1989.

${ }^{21}$ Gnoffo, P. A., Gupta, R. N. and Shinn, J. L., "Conservation Equations and Physical Models for Hypersonic Air Flows in Thermal and Chemical Nonequilibrium," NASA TP-2867, 1989. 